\title{
A Novel Glycine Receptor Variant with Startle Disease Affects Syndapin I and Glycinergic Inhibition
}

\author{
Georg Langlhofer, ${ }^{1}{ }^{\odot}$ Natascha Schaefer, ${ }^{1}{ }^{\circledR}$ Hans M. Maric, ${ }^{2,3}{ }^{\circledR}$ Angelo Keramidas, ${ }^{4}$ Yan Zhang, ${ }^{4}$ \\ Peter Baumann, ${ }^{1}{ }^{\circ}$ Robert Blum, ${ }^{1}$ Ulrike Breitinger, ${ }^{5}$ Kristian Strømgaard, ${ }^{2}$ Andreas Schlosser, ${ }^{3}$ \\ Michael M. Kessels, ${ }^{6}$ Dennis Koch, ${ }^{6}$ Britta Qualmann, ${ }^{6}$ Hans-Georg Breitinger, ${ }^{5}{ }^{\circledR}$ Joseph W. Lynch, ${ }^{4}$ and \\ Carmen Villmann ${ }^{1}$ \\ ${ }^{1}$ Institute for Clinical Neurobiology, University Hospital, Julius-Maximilians-University of Würzburg, 97070 Würzburg, Germany, ${ }^{2}$ Center for \\ Biopharmaceuticals, University of Copenhagen, 2100 Copenhagen, Denmark, ${ }^{3}$ Rudolf Virchow Center for Experimental Biomedicine, Julius- \\ Maximilians-University of Würzburg, 97080 Würzburg, Germany, ${ }^{4}$ Queensland Brain Institute, University of Queensland, St Lucia 4072, \\ Queensland, Australia, ${ }^{5}$ Department of Biochemistry, German University in Cairo, New Cairo City, Egypt, and ${ }^{6}$ Institute of Biochemistry I, \\ Jena University Hospital, University of Jena, 07743 Jena, Germany
}

Glycine receptors (GlyRs) are the major mediators of fast synaptic inhibition in the adult human spinal cord and brainstem. Hereditary mutations to GlyRs can lead to the rare, but potentially fatal, neuromotor disorder hyperekplexia. Most mutations located in the large intracellular domain (TM3-4 loop) of the GlyR $\alpha 1$ impair surface expression levels of the receptors. The novel GLRA1 mutation P366L, located in the TM3-4 loop, showed normal surface expression but reduced chloride currents, and accelerated whole-cell desensitization observed in whole-cell recordings. At the single-channel level, we observed reduced unitary conductance accompanied by spontaneous opening events in the absence of extracellular glycine. Using peptide microarrays and tandem MS-based analysis methods, we show that the proline-rich stretch surrounding P366 mediates binding to syndapin I, an F-BAR domain protein involved in membrane remodeling. The disruption of the noncanonical Src homology 3 recognition motif by P366L reduces syndapin I binding. These data suggest that the GlyR $\alpha 1$ subunit interacts with intracellular binding partners and may therefore play a role in receptor trafficking or synaptic anchoring, a function thus far only ascribed to the GlyR $\beta$ subunit. Hence, the P366L GlyR $\alpha 1$ variant exhibits a unique set of properties that cumulatively affect GlyR functionality and thus might explain the neuropathological mechanism underlying hyperekplexia in the mutant carriers. P366L is the first dominant GLRA1 mutation identified within the GlyR $\alpha 1$ TM3-4 loop that affects GlyR physiology without altering protein expression at the whole-cell and surface levels.

Key words: glycine receptor; hyperekplexia; PPII helix; syndapin I; TM3-4 loop

\section{Significance Statement}

We show that the intracellular domain of the inhibitory glycine receptor $\alpha 1$ subunit contributes to trafficking and synaptic anchoring. A proline-rich stretch in this receptor domain forms a noncanonical recognition motif important for the interaction with syndapin I (PACSIN1). The disruption of this motif, as present in a human patient with hyperekplexia led to impaired syndapin I binding. Functional analysis revealed that the altered proline-rich stretch determines several functional physiological parameters of the ion channel (e.g., faster whole-cell desensitization) reduced unitary conductance and spontaneous opening events. Thus, the proline-rich stretch from the glycine receptor $\alpha 1$ subunit represents a multifunctional intracellular protein motif.

Received Oct. 19, 2019; revised Mar. 24, 2020; accepted Apr. 24, 2020.

Author contributions: H.-G.B. and C.V. designed research; G.L., N.S., H.M.M., A.K., Y.Z., P.B., R.B., U.B., K.S., A.S., M.M.K., D.K., B.Q., H.-G.B., J.W.L., and C.V. performed research; R.B., K.S., and A.S. contributed unpublished reagents/analytic tools; G.L., N.S., H.M.M., A.K., Y.Z., P.B., U.B., K.S., A.S., M.M.K., D.K., B.Q., H.-G.B., J.W.L., and C.V. analyzed data; C.V. wrote the paper.

This work was supported by Deutsche Forschungsgemeinschaft Grants VI586 (C.V.), QU116/5, and DFG CRC166 (B.Q.). J.W.L. is supported by National Health and Medical Research Council Grant 1058542. G.L. was supported by the Graduate School of Life Sciences Würzburg as well as the Bayerische Forschungsstiftung. We thank Cord-Michael Becker for the assignment of blood samples from patients for research purposes. We also thank Nadine Vornberger for excellent technical assistance.

\section{Introduction}

Neurotransmission in the human CNS essentially relies on the balance of excitation and inhibition at synaptic sites. Ligandgated pentameric ion channels of the Cys-loop receptor (CLR)

The authors declare no competing financial interests.

Correspondence should be addressed to Carmen Villmann at Villmann_C@ukw.de.

https://doi.org/10.1523/JNEUROSCI.2490-19.2020

Copyright $\odot 2020$ the authors 
family, comprising excitatory serotonin [5-hydroxytryptamine $\left.\left(5-\mathrm{HT}_{3 \mathrm{~A}}\right)\right]$ and nicotinic acetylcholine receptors, inhibitory $\mathrm{GABA}_{\mathrm{A}}$ receptors, and glycine receptors (GlyRs), regulate the sensitive balance by selective permeation of cation and anions, respectively (Lynch, 2004). These ion channels feature a common structural organization. Every subunit is composed of an extracellular ligand binding domain, followed by four $\alpha$-helical transmembrane segments (TMs) that are connected by loops of various lengths and a short extracellular $\mathrm{C}$ terminus. While these elements share sequence similarities among different CLR family members, the large intracellular TM3-4 loop is considered to be the region with highest diversity and is part of the intracellular domain (ICD) of the receptor (Goyal et al., 2011). In prokaryotic CLR homologs, the TM3-4 loop is virtually absent (Bocquet et al., 2009; Hilf and Dutzler, 2009).

Synaptic GlyRs are predominantly expressed in the adult spinal cord and brainstem nuclei as heteropentameric proteins, where they act as key mediators of fast inhibition in motor reflex circuits (Yang et al., 2012; Patrizio et al., 2017). Human hyperekplexia (startle disease; Online Mendelian Inheritance in Man \#149400) is often caused by hereditary mutations in GlyR subunit genes (GLRA1, GLRB). Hyperekplexia is characterized by exaggerated startle episodes in response to unexpected stimuli, generalized and epileptic hypertonia, as well as muscle stiffness (Bakker et al., 2006). Mutated genes associated with the disease in the order of affected frequency are the GLRA1, SLC6A5 (glycine transporter 2), GLRB, GPHN (gephyrin), and ARHGEF9 (collybistin; Harvey et al., 2004; Carta et al., 2012; Bode and Lynch, 2014). Mutations in GLRA1 can lead to disturbances in receptor trafficking and receptor function (Chung et al., 2010).

In this study, we analyzed a novel dominant GLRA1 mutation P366L located in the TM3-4 loop of the GlyR $\alpha 1$ subunit focusing on ion channel expression and function (P366L numbering refers to the mature peptide of the short GlyR $\alpha 1$ isoform without the splice cassette SPMLNLFQ in the TM3-4 loop). So far, several hyperekplexia-associated mutations have been identified within the TM3-4 loop, all of which significantly reduced GlyR surface expression (Villmann et al., 2009). Unfortunately, information about the structure of the TM3-4 loop of any CLR members is sparse. However, molecular modeling and circular dicroism spectroscopy described $\alpha$-helical organizations close to TM3 and TM4 (Burgos et al., 2015). Furthermore, spectral signals of another secondary structure, a poly-proline helix type 2 (PPII) has been detected for the TM3-4 loop (Breitinger et al., 2004), forming a consensus sequence for binding to Src homology 3 (SH3) domains (Cascio et al., 2001). The PPII helix XXPXXP is highly conserved among all GlyR subunits with P366 being part of this structure. Notably, within the GlyR $\beta$ subunit, an overlapping region $\left({ }^{435} \mathrm{KPPPAKP}{ }^{441}\right)$ was shown to mediate the direct intracellular interaction with syndapin I (also called PACSIN1), a membrane-shaping F-BAR domain protein involved in membrane trafficking, cytoskeletal dynamics, synapse formation, and GlyR organization (Del Pino et al., 2014).

Here, we investigated the pathophysiology of a novel hyperekplexia mutation localized within the PPII helix in the GlyR $\alpha 1$ subunit, which revealed novel interaction partners of the synaptic glycine receptors. In this study, we used electrophysiological and biochemical techniques to understand the molecular mechanisms by which the GlyR mutant variant $\alpha 1^{\mathrm{P} 366 \mathrm{~L}}$ disrupted glycinergic signaling. We identified functional defects and an impaired syndapin I-mediated targeting that together likely contribute cumulatively to the hyperekplexia phenotype. Thereby, this study reveals a critical direct contribution of the intracellular
PPII helix within the GlyR $\alpha 1$ subunit to both receptor function and targeting, a function that so far has only been attributed to the GlyR $\beta$ subunit.

\section{Materials and Methods}

Direct sequencing from genomic DNA. Genomic DNA isolated from blood samples of male and female index patients was prepared according to the manufacturer protocol (DNeasy Blood and Tissue Kit, Qiagen). Specific intronic primers of the GLRA1 gene were used for PCR amplification of the appropriate exons followed by direct sequencing (LGC Genomics). These experiments were authorized by the Ethics Committee of the Medical Faculty of the University of Würzburg, Germany (reference no. 2019071702).

Site-directed mutagenesis. cDNAs encoding the human GlyR $\alpha 1$ wildtype $\left(\alpha 1^{\mathrm{wt}}\right)$ or mutated GlyR $\alpha 1\left[\alpha 1^{\mathrm{X}}\right.$, with $\mathrm{X}$ explaining the amino acid exchange of the mutant such as proline at position 366 into leucine (P366L)] were subcloned into the pRK5 expression vector. Mutations were introduced using site-directed mutagenesis. Primers (Thermo Fisher Scientific) contained the appropriate nucleotide exchanges. Mutated clones were sequenced to verify successful mutagenesis (Eurofins Genomics).

Animals. CD1 (strain \#022, Charles River Laboratories) and C57BL/ 6 (stock \#664, The Jackson Laboratory) pregnant female mice were used to isolate embryonic hippocampal cultures. Brain tissue was isolated from adult male mice. All experiments were performed in accordance with the guidelines set by the European Union and approved by our institutional Animal Care Committee, the Utilization Committee, and the Regierung von Unterfranken (Würzburg, Germany). At embryonic day 15 (E15) pregnant Wistar rats were killed via $\mathrm{CO}_{2}$ inhalation, as approved by the University of Queensland Animal Ethics Committee, Australia (QBI/203/13/ARC).

Cell lines and transfection. HEK293 cells (ATCC CRL-1573) were grown in Life Technologies Minimum Essential Medium (Thermo Fisher Scientific) supplemented with $10 \%$ fetal calf serum (FCS), glutaMAX $(200 \mathrm{~mm})$, sodium pyruvate $(100 \mathrm{~mm})$, and penicillin $(10,000$ $\mathrm{U} / \mathrm{ml}) /$ streptomycin $(10,000 \mu \mathrm{g} / \mathrm{ml})$. The cells were incubated at $37^{\circ} \mathrm{C}$ and $5 \% \mathrm{CO}_{2}$. HEK293 cells were transiently transfected with $1 \mu \mathrm{g}$ of cDNA at $75 \%$ confluency of cells using a modified calcium-phosphate precipitation method. For visualization in electrophysiological recordings $1 \mu \mathrm{g}$ of green fluorescent protein (GFP) cDNA was cotransfected. For pull-down experiments, HEK293 cells were transfected with GlyR $\alpha 1$ using Lipofectamine 2000 (Thermo Fisher Scientific).

Artificial synapse formation. Primary cultures of embryonic spinal cord neurons were prepared as described previously (Zhang et al., 2015). Following dissection of the spinal cord, the tissue was trypsinized [10 $\mathrm{ml}$ of trypsin/EDTA $(1 \mathrm{mg} / \mathrm{ml})$ supplemented with $100 \mu \mathrm{l}$ of DNase I, final concentration, $0.1 \mathrm{mg} / \mathrm{ml}$ ] for $30 \mathrm{~min}$ at $37^{\circ} \mathrm{C}$. One milliliter of FCS (final concentration, 10\%) was added to stop the digestion. Cell were gently triturated using a fire-polished Pasteur pipette. A total of 80,000 cells were seeded on poly-D-lysine-coated coverslips with a diameter of 18 $\mathrm{mm}$ in Neurobasal medium supplemented with 2\% B27 and 1\% GlutaMax (Thermo Fisher Scientific). Neurons were maintained in culture for up to 4 weeks. One to $3 \mathrm{~d}$ before recordings, heterosynaptic cocultures were prepared by plating HEK293 cells $24 \mathrm{~h}$ post-transfection with either GlyR $\alpha 1^{\mathrm{wt}}$ or GlyR $\alpha 1^{\mathrm{P} 366 \mathrm{~L}}$ onto the primary neuronal cultures.

Hippocampal cultures. Hippocampal neurons were prepared from embryonic CD1 mouse embryos at stage E18. Mice were killed, and hippocampi were dissected. Hippocampi were trypsinized using $10 \mathrm{ml}$ of trypsin/EDTA $(1 \mathrm{mg} / \mathrm{ml}$ ) and $100 \mu \mathrm{l}$ of DNase I (final concentration, $0.1 \mathrm{mg} / \mathrm{ml}$ ) for $30 \mathrm{~min}$ at $37^{\circ} \mathrm{C}$. Trypsinization was stopped with $1 \mathrm{ml}$ of FCS (final concentration, 10\%). Hippocampal neurons were triturated three times. Supernatants with cells were centrifuged at $800 \mathrm{rpm}$ for $10 \mathrm{~min}$. Cells were counted and plated on poly-D-lysine-coated coverslips using a density of 150,000 cells $/ 3 \mathrm{~cm}$ dish. Neurons were grown in Life Technologies Neurobasal medium (Thermo Fisher Scientific) containing $5 \mathrm{ml}$ of L-glutamine (200 mM) and Life Technologies B27 supplement (Thermo Fisher Scientific) with an exchange of $50 \%$ medium after $7 \mathrm{~d}$ in 
culture. Neurons older than day in vitro 13 (DIV13) were used for experiments.

Lentiviral vector. cDNAs encoding the human GlyR $\alpha 1$ wild-type $\left(\alpha 1^{\mathrm{wt}}\right)$ or GlyR $\alpha 1^{\mathrm{P} 366 \mathrm{~L}}$ were cloned into a modified form of the lentiviral transfer vector pFUGW (Lois et al., 2002), resulting in hGlyR $\alpha 1^{\text {IRES }} \mathrm{GFP}$ and hGlyR $\alpha 1^{\text {P366L-IRES }}$ GFP (in which " $h$ " signifies human). To monitor transduced cells, all vectors express GFP under control of an internal ribosomal entry site 2 (IRES2). Lentiviral particles were produced in HEK293T cells. For this, the lentiviral expression vectors were cotransfected with a pseudotyping vector (pMD2.G), expressing VSV-G (vesicular stomatitis virus $G$ ) protein, and the packaging vector $p C M V \Delta R 8.91$ (Zufferey et al., 1998) using Lipofectamine 2000 (Thermo Fisher Scientific). Lentiviral particles were separated from the supernatant by ultracentrifugation and stored at $-80^{\circ} \mathrm{C}$ as follows (in mM): 50 Tris$\mathrm{HCl}, \mathrm{pH} 7.8,130 \mathrm{NaCl}, 10 \mathrm{KCl}, 5 \mathrm{MgCl}_{2}$. The number of infectious particles was determined using serial dilutions of the viral vectors on HEK293T cells. For transduction of hippocampal neurons, a multiplicity of infection of 20 was used. Neuronal transduction was performed during cell seeding. Hippocampal neurons were analyzed at DIV 14.

Immunocytochemical stainings: HEK293 cells. To label surface receptors only, live stain experiments on transfected HEK293 cells were performed. Cells were incubated with the GlyR $\alpha 1$-specific antibody mAb2b (residues 1-10 of the mature GlyR $\alpha 1$; catalog \#146111, Synaptic Systems). After primary antibody incubation, cells were fixed with $4 \%$ paraformaldehyde (PFA) and $4 \%$ sucrose in phosphate-buffered saline (PBS). In contrast to surface GlyR $\alpha 1$, whole-cell GlyRs were stained following fixation, blocking and permeabilization (0.1\% Triton X-100, 5\% NGS in PBS) with the pan- $\alpha$ antibody mAb4a. MAb4a recognizes a denatured N-terminal epitope at fixed cells (residues 96-105, catalog \#146011, Synaptic Systems). Cells were incubated with secondary antibody goat-anti-mouse Cy3 (1:500; Dianova) for $1 \mathrm{~h}$. After washing with PBS cells were incubated with DAPI (1:5000) for $5 \mathrm{~min}$ and mounted with Mowiol.

Hippocampal neurons. At DIV15, live cell stainings of surface GlyRs were performed using the $\alpha 1$-specific mAb2b antibody for $2 \mathrm{~h}$ at $4^{\circ} \mathrm{C}$. After 20 min of fixation (4\% PFA, 4\% sucrose), cells were blocked and permeabilized with $5 \%$ goat serum and $0.1 \%$ Triton X-100 for $30 \mathrm{~min}$. Endogenous syndapin I was stained overnight with the rabbit anti-syndapin I antibody (Qualmann et al., 1999) at $4^{\circ} \mathrm{C}$. Subsequently, cells were washed and incubated with secondary antibodies goat-anti-mouse Cy3 and goat-anti-rabbit Cy5 (Dianova) for $2 \mathrm{~h}$ at room temperature. Following DAPI staining (1:5000), cover slips were mounted with Mowiol.

Data analysis for quantification of syndapin I was performed using the software Openview described in the study by Tsuriel et al. (2006). The signal of the stained GlyR $\alpha 1$ (mAb2b) was used as a mask. Syndapin I signal intensities were measured within mAb2b clusters and separated into whole-cell, soma, and neurite signals (three independent experiments; 4-7 z-projections were analyzed).

Biotinylation of cell surface protein. Forty-eight hours post-transfection, cell surface biotinylation experiments were performed from transfected HEK293 cells, as described previously (Atak et al., 2015). Following incubation of the transfected cells with biotin and an additional quenching step, cells were lysed, and membrane proteins solubilized in Tris-buffered saline (TBS: $50 \mathrm{~mm}$ Tris, $150 \mathrm{~mm} \mathrm{NaCl}, \mathrm{pH}$ 8.0) containing $0.1 \%$ Triton X-100, $0.1 \mathrm{~mm}$ PMSF, $2 \mathrm{~mm}$ EDTA, and cOmplete, EDTA-free protease inhibitor cocktail (Roche). Following centrifugation, supernatants were taken as whole-cell fraction. The supernatant was further supplied with streptavidin beads to bind surfaceexposed labeled proteins. The bead fraction therefore represents the surface pool. Whole-cell and surface fractions were separated on $11 \%$ SDS-PAGE gels. Western blots were labeled with mAb4A for GlyR $\alpha$ receptor protein and a pan-cadherin antibody (Cell Signaling Technology). Cadherin was used as a membrane marker protein.

Immunoprecipitation. HEK293 cells were grown on $10 \mathrm{~cm}$ dishes as described above and used $48 \mathrm{~h}$ after transfection. Cells were washed once with PBS and cell lysis was performed with TBS with $1 \%$ Triton X-100 and cOmplete EDTA-free protease inhibitor cocktail (Roche). Fifty microliters of $10 \%$ DOC solution $[10 \%(\mathrm{w} / \mathrm{v})$ sodium-deso- xycholate in $20 \mathrm{~mm}$ Tris/HCl, $\mathrm{pH} 9.0$ ] was added to $600 \mu \mathrm{l}$ of cell lysate and rotated for $10 \mathrm{~min}$ at $22^{\circ} \mathrm{C}$. Probes were centrifuged for $1 \mathrm{~min}$ at $13,000 \times g$, and the supernatant was used as input for coimmunoprecipitation experiments. The protein solution $(450 \mu \mathrm{l})$ was supplemented with mAb2b antibody (1:200; Synaptic Systems) and $50 \mu \mathrm{l}$ of protein ASepharose beads/protein G-agarose mix (1:1; GE Healthcare), and agitated overnight at $4^{\circ} \mathrm{C}$. Following a short centrifugation step, the supernatant was removed. The beads were washed three times with NET buffer (160 mm NaCl, 5 mm EDTA, 1\% TritonX-100 in $50 \mathrm{~mm}$ Tris $\mathrm{HCl}$, $\mathrm{pH} 8$ ). Proteins were eluted from beads by incubating in $30 \mu \mathrm{l}$ of $2 \times$ SDS sample buffer at $95^{\circ} \mathrm{C}$ for $7 \mathrm{~min}$. Proteins were separated on $11 \%$ SDS gels and stained after Western blotting with rabbit anti-syndapin I antibody (catalog \#196002, Synaptic Systems) and afterward with mouse anti-GlyR pan- $\alpha$ antibody (catalog \#146011, Synaptic Systems) for input detection and precipitation control of the GlyR.

Electrophysiological whole-cell recordings. Whole-cell patch-clamp recordings were used to measure maximal currents $\left(I_{\max }\right)$ from transfected HEK293 cells $48 \mathrm{~h}$ post-transfection. Signals were amplified with an EPC 9 amplifier controlled by Pulse Software (HEKA). One millimolar glycine was applied using a U-tube system, which enabled bathing the suspended cell in a laminar flow of solution with a time resolution for equilibration of 10-30 ms. The external buffer consisted of the following (in mM): $137 \mathrm{NaCl}, 5.4 \mathrm{KCl}, 1.8 \mathrm{CaCl}_{2}, 1 \mathrm{MgCl}_{2}$, and $5 \mathrm{HEPES}$, with $\mathrm{pH}$ adjusted to 7.4 with $\mathrm{NaOH}$. The internal buffer was as follows (in mM): $120 \mathrm{CsCl}, 20 \mathrm{~N}(\mathrm{Et}){ }_{4} \mathrm{Cl}, 1 \mathrm{CaCl}_{2}, 2 \mathrm{MgCl}_{2}, 11 \mathrm{EGTA}$, and 10 HEPES, with $\mathrm{pH}$ adjusted to 7.2 with $\mathrm{CsOH}$. Recording pipettes were fabricated from borosilicate capillaries (World Precision Instruments) with an open resistance of 6-8 M . Cells were held at $-60 \mathrm{mV}$, and recordings were performed at room temperature $\left(\sim 22^{\circ} \mathrm{C}\right)$.

Concentration-response curves were constructed from the peak current amplitudes obtained with at least seven appropriately spaced concentrations in the range 3-1000 $\mu \mathrm{M}$ glycine. Using a nonlinear algorithm (Microcal Origin Software), concentration-response data were first ana-

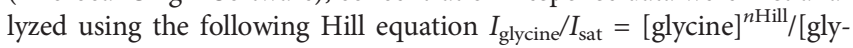
cine] $n_{\mathrm{H}}+E C_{50} n_{\mathrm{H}}$, where $I_{\text {glycine }}$ refers to the current amplitude at a given glycine concentration, $I_{\text {sat }}$ is the current amplitude at saturating concentrations of glycine, $\mathrm{EC}_{50}$ is the glycine concentration producing half-maximal current responses, and $n_{\mathrm{H}}$ is the Hill coefficient.

For desensitization analysis, whole-cell current traces were transferred to Microcal Origin (Microcal Origin Software). The equation of a single exponential function plus a constant was used to analyze the decay currents in presence of $1 \mathrm{~mm}$ glycine, as follows:

$$
I_{\mathrm{obs}}=I_{1} \times e^{(-t / r 1)}+I_{\text {const }} .
$$

$I_{\text {obs }}$ represents the observed total current amplitude, $I_{1}$ the fraction of current desensitizing with the time constant $\tau_{1}$, and $I_{\text {const }}$ is the amplitude of the nondesensitizing current fraction. A single exponential decay plus a constant current term were sufficient to describe desensitization behavior. The desensitizing current fractions were calculated by fitting the curves from the peak current of the trace to the $2 \mathrm{~s}$ time point where glycine application ended.

Estimated data were compared using the one-sample $t$ test (GraphPad Prism, GraphPad Software) followed by Bonferroni post hoc test, with a probability of error of $p<0.05$ considered significant.

Electrophysiological single-channel recordings. To minimize the formation of homomeric receptors, heteromeric GlyRs were expressed by cotransfecting the cDNAs encoding the $\alpha 1$ and $\beta$ subunits at an $\alpha 1 / \beta$ ratio of 1:100. All recordings were performed at room temperature $\left(22 \pm 1^{\circ} \mathrm{C}\right)$ at a clamped potential of $-70 \mathrm{mV}$, unless otherwise indicated, in an outside-out patch configuration. The intracellular solution was composed of the following (in $\mathrm{mM}$ ): $145 \mathrm{CsCl}, 2 \mathrm{CaCl}_{2}, 2 \mathrm{MgCl}_{2}, 10$ HEPES, and 10 EGTA, adjusted to $\mathrm{pH} 7.4$ with $\mathrm{CsOH}$. The extracellular solution was composed of the following (in $\mathrm{mm}$ ): $140 \mathrm{NaCl}, 5 \mathrm{KCl}, 2$ $\mathrm{CaCl}_{2}, 1 \mathrm{MgCl}_{2}, 10 \mathrm{HEPES}$, and $10 \mathrm{D}$-glucose, adjusted to $\mathrm{pH} 7.4$ with $\mathrm{NaOH}$. The single-channel conductance $(\gamma)$ was determined by constructing current-voltage $(I-V)$ plots from data obtained at clamped voltages of $\pm 70, \pm 35, \pm 15$, and $0 \mathrm{mV}$. The conductance was calculated using the following: 


$$
\gamma=\frac{i}{V_{\text {hold }}-V_{\mathrm{ljp}}-V_{\text {rev }}},
$$

where $i$ is the unitary (single-channel) current, $V_{\text {hold }}$ is the holding potential $(-70 \mathrm{mV}), V_{\text {ljp }}$ is the liquid junction potential, and $V_{\text {rev }}$ is the reversal potential. $V_{\mathrm{ljp}}$ was calculated to be $4.7 \mathrm{mV}$, and $V_{\text {rev }}$ was estimated directly from the $I-V$ plots. Single-channel currents were recorded using an Axon 200B amplifier (Molecular Devices), filtered $(-3 \mathrm{~dB}$, four-pole Bessel) at $5 \mathrm{kHz}$ and sampled at $50 \mathrm{kHz}$. Currents were filtered offline to $5 \mathrm{kHz}$ for making figures.

Voltage-clamp fluorometry. Oocytes from female Xenopus laevis (Xenopus Express) were prepared as previously described (Pless et al., 2007) and injected with $10 \mathrm{ng}$ of mRNA. The oocytes were then incubated at $18^{\circ} \mathrm{C}$ for $3-5 \mathrm{~d}$ in ND96 solution containing in the following (mM): $96 \mathrm{NaCl}, 2 \mathrm{KCl}, 1 \mathrm{MgCl}_{2}, 1.8 \mathrm{CaCl}_{2}, 5$ HEPES, 0.6 theophylline, 2.5 pyruvic acid, and $50 \mu \mathrm{g} / \mathrm{ml}$ gentamycin, $\mathrm{pH}$ 7.4. Frog animal experiments were approved by University of Queensland Animal Ethics Committee (Approval no. QBI/059/13/ARC/NHMRC). Rhodamine methanethiosulfonate (MTSR) and 2-((5(6)-tetramethylrhodamine) carboxylamino) ethyl methanethiosulfonate (MTS-TAMRA; both from Toronto Research Chemicals) were dissolved in dimethylsulfoxide (DMSO) and stored at $-20^{\circ} \mathrm{C}$. On the day of recording, oocytes were incubated for $30 \mathrm{~s}$ in $10 \mu \mathrm{M}$ MTSR or MTS-TAMRA dissolved in icecold ND96. Oocytes were then thoroughly washed and stored in ND96 for up to $6 \mathrm{~h}$ on ice before recording. Oocytes were placed in a recording chamber on an inverted microscope. The microscope was equipped with a high-Q tetramethylrhodamine isothiocyanate filter set (Chroma Technology, a Plan Fluor $40 \times$ objective lens (Nikon Instruments), and a Hamamatsu H7360-03 photomultiplier (Hamamatsu Photonics) coupled to a PMT400R photomultiplier subsystem (Ionoptix). A $150 \mathrm{~W}$ halogen lamp was used as light source. Cells were maintained at $-40 \mathrm{mV}$ by conventional two-electrode voltage clamp, and currents were recorded with a Gene Clamp 500B amplifier (Molecular Devices). Current and fluorescence traces were acquired at $200 \mathrm{~Hz}$ via a Digidata 1322A interface using Clampex 9.2 software (Molecular Devices). For analysis and display, fluorescence signals were digitally filtered at $1-2 \mathrm{~Hz}$ with an eight-pole Bessel filter. Results are expressed as the mean \pm SEM of three or more independent experiments.

Preparation of whole-brain lysates. After cervical dislocation, whole brains from adult male/female C57BL/6 wild-type mice were removed from the scull and rapidly cooled to $4^{\circ} \mathrm{C}$. Brain tissue was homogenized with $1 \mathrm{ml}$ lysate buffer per $200 \mathrm{mg}$ using a pistol homogenizer with eight strokes at $900 \mathrm{rpm}$. Lysate buffer contained the following (mM): 20 HEPES, $100 \mathrm{KCH}_{3} \mathrm{COOH}, 40 \mathrm{KCl}$, 5EGTA, $5 \mathrm{MgCl}_{2}$, 5 DTT, 1 PMSF, $1 \%$ Triton X-100, and cOmplete EDTA-free protease inhibitor cocktail (Roche). The homogenate was centrifuged at $10,000 \times g$ and $4^{\circ} \mathrm{C}$ for $15 \mathrm{~min}$. The supernatant was aliquoted and flash frozen in liquid nitrogen, and stored at $-80^{\circ} \mathrm{C}$.

Peptide synthesis. Peptides were synthesized as C-terminal amides in $50 \mu \mathrm{mol}$ scale using a Life Technologies PAL-PEG-PS resin (Thermo Fisher Scientific) with a specific loading of $0.18 \mathrm{mmol} / \mathrm{g}$. Automated microwave-assisted solid-phase peptide synthesis (SPPS) was conducted in a Liberty Blue microwave peptide synthesizer (CEM) with a $30 \mathrm{ml}$ Teflon reaction vessel using peptide reagent from Sigma-Aldrich Chemie and Iris Biotech. Fluorenylmethoxycarbonyl protecting group (Fmoc)-protected amino acids were dissolved $(0.2 \mathrm{M})$ in dimethylformamide (DMF). The activator solution was $\mathrm{N}, \mathrm{N}^{\prime}$-diisopropylcarbodiimide (DIC; $0.5 \mathrm{M}$ ) in DMF with diisopropylethylamine (DIPEA; 0.01\%), and ethyl 2-cyano-2-(hydroxyimino) acetate (Oxyma; $1 \mathrm{M}$ ) in DMF with DIPEA (0.01\%). Microwave assisted synthesis was conducted based on the following protocol: deprotection $\left(150 \mathrm{~W}, 15 \mathrm{~s}, 75^{\circ} \mathrm{C}\right.$, followed by 30 $\left.\mathrm{W}, 60 \mathrm{~s}, 90^{\circ} \mathrm{C}\right)$, coupling $\left(190 \mathrm{~W}, 180 \mathrm{~s}, 75^{\circ} \mathrm{C}\right.$, followed by $36 \mathrm{~W}, 120 \mathrm{~s}$, $\left.90^{\circ} \mathrm{C}\right)$. Double coupling by Oxyma/DIC/amino acid in the relation $(1: 1: 1$ equivalence) in fivefold excess over the resin loading achieved peptide elongation. Peptide cleavage from the solid support was conducted by treatment of the resin for $2 \mathrm{~h}$ with a cleavage mixture containing trifluoroacetic acid (TFA)/triisopropylsilane (TIPS) $/ \mathrm{H}_{2} \mathrm{O} /$ ethanedithiol/ thioanisol (90:2.5:2.5:2,5:2,5, $3 \mathrm{ml}$ ). Peptides were precipitated in diethyl ether $\left(-20^{\circ} \mathrm{C}\right)$ spun down and washed two more times. The pellets were dissolved in $50 \% \mathrm{H}_{2} \mathrm{O}, 50 \% \mathrm{ACN}$, and $0.1 \% \mathrm{TFA}$, and purified by reverse-phase HPLC (Waters) with a ZORBAX 300SB-C18 PrepHT column $(21.2 \times 250 \mathrm{~mm}, 7 \mathrm{~mm}$; Agilent Technologies $)$ using a gradient of $20-50 \%$ acetonitrile over $25 \mathrm{~min}$. Fractions $(10 \mathrm{ml})$ were collected. Pure fractions were identified based on liquid chromatography (LC)-MS, and the purity of the pooled peptide fractions was determined by ultra-performance LC after lyophilization on a freeze dryer.

Peptide microarray synthesis. For screening in microarray format, peptides were synthesized using a ResPep SL synthesis robot equipped with a Celluspot synthesis module and printed using a Slide spotter (Intavis AG). All peptides were synthesized in parallel on acid-soluble Fmoc- $\beta$-alanine etherified cellulose disks (area $0.12 \mathrm{~cm}^{2}$, loading $1.0 \mu \mathrm{mol} / \mathrm{cm}^{2}$; Intavis AG). Synthesis was based on Standart Fmoc-based SPPS using reagents from Sigma-Aldrich Chemie and Iris Biotech. Amino acids were coupled by adding two times $1.2 \mu \mathrm{l}$ Oxyma/DIC/ amino acid in the relation (1.1:1.5:1.0). Residual unreacted binding sites were capped by the addition of $4 \mu \mathrm{l}$ of $10 \%$ acetic anhydride solution in DMF. Peptide deprotection was performed using $150 \mu$ l per disk of a side chain deprotection solution (TFA/TIPS/water/DCM: $80 \%, 3 \%, 5 \%$, $12 \%)$ for $2 \mathrm{~h}$ at room temperature. Disks were then solubilized overnight in $250 \mu \mathrm{l}$ of cellulose solvation solution (TFA/trifluoromethansulfonic acid/TIPS/water: $88.5 \%, 4 \%, 2.5 \%, 5 \%)$. Seven hundred fifty microliters of diethyl ether $\left(-20^{\circ} \mathrm{C}\right)$ was added to the dissolved cellulose-peptide conjugates. The mixture was briefly agitated and precipitated at $-20^{\circ} \mathrm{C}$ for $1 \mathrm{~h}$. Precipitated conjugates were pelleted by centrifugation at 2000 $\times g$. The pellet was additionally washed twice with fresh cold ether. After the final washing step, residual ether was evaporated and $500 \mu \mathrm{l}$ of DMSO was added to resolve the cellulose-peptide conjugates. The cellulose-peptide conjugate stock solutions were stored at $-20^{\circ} \mathrm{C}$. Fifty microliters of peptide stock solutions were transferred to a 384-well plate, and mixed 5:1 with SSC buffer $\left(150 \mu \mathrm{M} \mathrm{NaCl}, 15 \mu \mathrm{M} \mathrm{Na}{ }_{3} \mathrm{C}_{6} \mathrm{H}_{5} \mathrm{O}_{7}\right.$, $\mathrm{pH}$ 7.0). Thirty nanoliters of each peptide was transferred to each position on coated glass slides with the slide spotter (Intavis AG).

Peptide array analysis. After drying overnight, the arrays were washed and equilibrated with TBS, pH 7.6. Syndapin I full length, syndapin I lacking the $\mathrm{SH} 3$ domain ( $\mathrm{sdpI}^{\mathrm{\Delta SH} 3}$ ), as well as whole-brain lysate were incubated on the arrays at $4^{\circ} \mathrm{C}$ for $1 \mathrm{~h}$. Protein binding to the spotted peptides was detected by chemiluminescence after Western analysis with antibodies. The resulting dot blots were analyzed using the array Analyze software (Active Motif), which defines the error range of each dataset by comparing the intensities of each peptide duplicate on the analyzed array. For following calculations, we only included peptide array datasets where $>90 \%$ of the peptide spots were within a $<5 \%$ error margin. The spot densities of the accepted datasets were then normalized against wild-type intensity, as indicated. Three peptide array duplicates, resulting in eight datasets of $8 \times 240$ peptides were used to calculate the average spot densities and the rms deviations.

Covalent immobilization of peptides. Purified cysteine containing peptides were coupled covalently to Ultra Link iodoacetyl resin (Thermo Fisher Scientific). Peptides were dissolved in coupling buffer $(50 \mathrm{~mm}$ Tris, $5 \mathrm{~mm}$ EDTA, $\mathrm{pH} 8.5$ ) at a concentration of $1 \mathrm{~mm}$ and incubated for $2 \mathrm{~h}$ at room temperature $\left(\sim 22^{\circ} \mathrm{C}\right)$ with washed and equilibrated UltraLink beads. After removing excess peptides, the unreacted iodoacetyl groups on the UltraLink beads were quenched with $1 \mathrm{~mm}$ cysteine for $2 \mathrm{~h}$. The resin was washed three times and stored at $4^{\circ} \mathrm{C}$.

Protein pulldown from brain lysate. Incubation, washing and elution of the resin was executed in $400 \mu \mathrm{l}$ micro-spin columns (Thermo Fisher Scientific). Whole-brain lysate from adult C57BL/6 mice (male) was incubated on the immobilized peptides for $1 \mathrm{~h}$ at $4^{\circ} \mathrm{C}$. The resin was washed five times with lysate buffer. Bound proteins were eluted with Laemmli buffer containing $10 \% \mathrm{SDS}$ at $90^{\circ} \mathrm{C}$ for $3 \mathrm{~min}$. The eluate was applied to gel electrophoresis and after in-solution digestion analyzed via nanoLC-MS/MS (tandem mass spectrometry).

In-solution digestion. Proteins were reduced in $50 \mathrm{~mm}$ dithiothreitol (DTT) for $10 \mathrm{~min}$ at $90^{\circ} \mathrm{C}$ and alkylated with $120 \mathrm{~mm}$ iodoacetamide for $20 \mathrm{~min}$ at room temperature in the dark. Protein precipitation was performed according to the study by Wessel and Flügge (1984) with 
chloroform/methanol. Precipitated proteins were dissolved in $0.5 \%$ sodium deoxycholate (SDC; Sigma-Aldrich) in $100 \mathrm{~mm}$ ammonium bicarbonate. Digests were performed with $0.1 \mu \mathrm{g}$ of trypsin overnight at $37^{\circ} \mathrm{C}$. SDC was removed by extraction with ethyl acetate (Masuda et al., 2008). Peptides were dried in a vacuum concentrator (Concentrator 5301, Eppendorf) to remove remaining ethyl acetate. Peptides were desalted using C18 stage tips (Rappsilber et al., 2003). Each stage tip was prepared with three disks of C18 Empore SPE Disks (3 M) in a $200 \mu$ l pipette tip. Peptides were eluted with $60 \%$ acetonitrile in $0.3 \%$ formic acid, dried in a vacuum concentrator, and stored at $-20^{\circ} \mathrm{C}$. Peptides were dissolved in $2 \%$ acetonitrile $/ 0.1 \%$ formic acid before nanoLCMS/MS analysis.

nanoLC-MS/MS analysis. nanoLC-MS/ MS analyses were performed on an Orbitrap Fusion (Thermo Fisher Scientific) equipped with an EASY-Spray Ion Source and coupled to an EASY-nLC 1000 (Thermo Fisher Scientific). Peptides were loaded on a trapping column $[2 \mathrm{~cm} \times$ $75 \mu \mathrm{m}$ inner diameter (i.d.); PepMap C18, $3 \mu \mathrm{m}$ particles, $100 \AA$ pore size] and separated on an EASY-Spray column $(50 \mathrm{~cm} \times$ $75 \mu \mathrm{m}$ i.d.; PepMap C18, $2 \mu \mathrm{m}$ particles, $100 \AA$ pore size) with a 120 min linear gradient from $3 \%$ to $40 \%$ acetonitrile and $0.1 \%$ formic acid.

Both MS and MS/MS scans were acquired in the Orbitrap analyzer with a resolution of 60,000 for MS scans, and 15,000 for MS/MS scans. Higher-energy collisional dissociation with $35 \%$ normalized collision energy was applied. A top speed data-dependent MS/MS method with a fixed cycle time of $3 \mathrm{~s}$ was used. Dynamic exclusion was applied with a repeat count of 1 and an exclusion duration of $120 \mathrm{~s}$. Singly charged precursors were excluded from selection. Minimum signal threshold for precursor selection was set to 50,000. Predictive automatic gain control (AGC) was used with AGC a target value of $5 \mathrm{e} 5$ for MS scans and 5e4 for MS/MS scans. EASY-IC was used for internal calibration.

MS data analysis. Raw MS data files were analyzed with MaxQuant version 1.6.2.2 (Cox and Mann, 2008). A database search was performed with Andromeda, which is integrated in the used version of MaxQuant. The search was performed against the UniProt Mouse database. Additionally, a database containing common contaminants was used. The search was performed with tryptic cleavage specificity with three allowed miscleavages.

Protein identification was under control of the false discovery rate (FDR; $<1 \%$ FDR on protein and peptide level). In addition to MaxQuant default settings, the search was performed against the following variable modifications: protein N-terminal acetylation; glutamine [Gln to pyroGlu formation (N-terminal Gln); and oxidation (Met). Carbamidomethyl (Cys) was set as fixed modification. For protein quantitation, the labelfree quantification (LFQ) intensities were used. Proteins with less than two identified razor/unique peptides were dismissed.

Further data analysis was performed using R scripts developed inhouse. For the discrimination of unspecific enriched proteins, median LFQ intensities were calculated. Missing LFQ intensities were imputed with values close to the baseline. Data imputation was performed with values from a standard normal distribution with a mean of the $5 \%$ quantile of the combined log10-transformed LFQ intensities and an SD of 0.1 . For the identification of significantly enriched proteins, boxplot outliers were identified in intensity bins of at least 300 proteins. Log2-transformed protein ratios of samples from different peptide pulldowns with values outside a $1.5 \times($ significance 1$)$ or $3 \times($ significance 2$)$ interquartile range, respectively, were considered as significantly enriched.
C

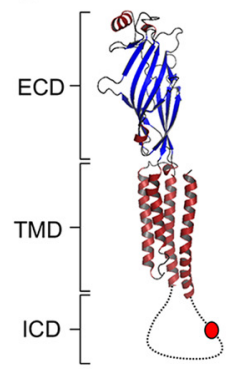

$\alpha 1^{\mathrm{w}}$

$\alpha 1^{\mathrm{P} 366 \mathrm{~L}}$

$\alpha 1^{\mathrm{P} 366 \mathrm{C}}$

$\alpha 1^{\mathrm{P} 366 \mathrm{~A}}$

$\alpha 1^{\mathrm{P} 366 \mathrm{R}}$

$\alpha 1^{\mathrm{P} 366 \mathrm{~T}}$

$\alpha 1^{\mathrm{P} 366 \mathrm{~W}}$

$\alpha 1^{\mathrm{P} 373 \mathrm{~A}}$

$\alpha 1^{\mathrm{P} 1-4 \mathrm{~A}}$

$\alpha 1^{\mathrm{P} 1-5 \mathrm{~A}}$

$\alpha 1^{\mathrm{P} 1-5 \mathrm{~L}}$

$\alpha 1^{\triangle \mathrm{P} 1-4}$

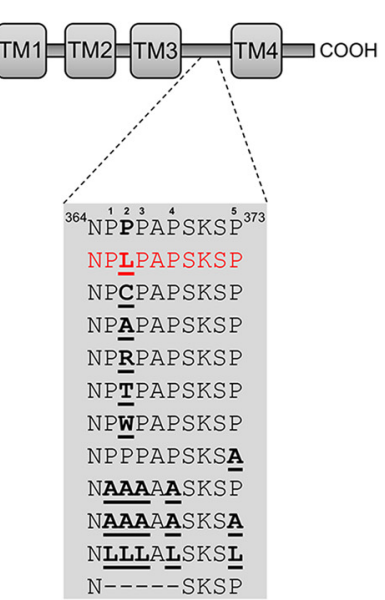

Figure 1. Localization of the human P366L GlyR $\alpha 1$ variant. $\boldsymbol{A}$, Family tree of the affected P366L patient (II/1). The dominant mode of inheritance demonstrates the mother $(I / 2)$ as the carrier of the P366L mutation, while the father (I/1) was unaffected. dues within the TM3-4 loop (black background). C, Cryo-EM structure of a single Danio rerio GlyR $\alpha 1$ subunit (Du et al., 2015). .

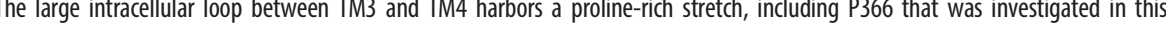
study. A series of point mutations and combined mutations were generated (bold, underlined) to analyze the influence of prolines NPPPAPSKSP ${ }^{373}$ on GlyR $\alpha 1$ function.

Experimental design and statistical analysis. All experiments have been performed as at least three independent biological replicates (unless otherwise stated). The number of experiments or cells recorded for analyses is presented in the Results referring to the appropriate experiments.

Quantification of GlyR protein-mAb4A signals for each expressed variant were normalized to pan-cadherin signals and adjusted to GlyR $\alpha 1$ wild type. Calculated data were compared using ANOVA with a probability of error of $p<0.05$ considered to be significant.

Quantification of data obtained from electrophysiological recordings: estimated data were compared using the unpaired two-tailed $t$ test (GraphPad Prism, GraphPad Software or SigmaPlot Software) with a probability of error of $p<0.05$ was considered to be significant. For statistical analysis of data comparing glycine-induced inward currents or desensitization behavior of GlyR $\alpha 1^{\text {wt }}$ with mutant GlyRs affected at position P366 or within the sequence ${ }^{364}$ NPPPAPSKSP ${ }^{373}$, data for each mutant were compared with GlyR $\alpha 1^{\text {wt }}$ of the same experiment.

Binding affinities of various $\operatorname{GlyR} \alpha$ peptides to syndapin were validated using the two-tailed $t$ test with $p<0.05$ considered to be significant.

For statistical analysis of endogenous syndapin I and GlyR $\alpha 1$ following infection into hippocampal neurons, syndapin I signals were normalized to GlyR $\alpha 1$ input signals and adjusted to wild type. Calculated data were compared using ANOVA with a probability of error of $p<0.05$ considered to be significant.

\section{Results}

\section{Description of the pedigree}

A novel hyperekplexia mutation GlyR $\alpha 1^{\mathrm{P} 366 \mathrm{~L}}$ (in short $\alpha 1^{\mathrm{P} 366 \mathrm{~L}}$ ) was identified in the coding region of GLRA1 from a patient with symptoms characteristic of this neurologic disorder. Pedigree analysis revealed that $\alpha 1^{\mathrm{P} 366 \mathrm{~L}}$ showed a dominant mode of inheritance (Fig. 1A). Proline 366 is located in the TM3-4 loop. Sequence alignment with other members of the CLR family indicates a high degree of conservation of this residue (Fig. 1B). While the transmembrane domains as well as the extracellular ligand-binding domain of GlyR $\alpha 1$ have been crystallized, little 


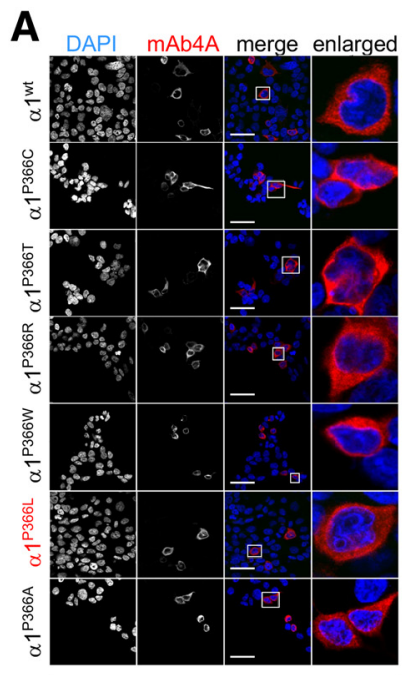

permeabilized
B

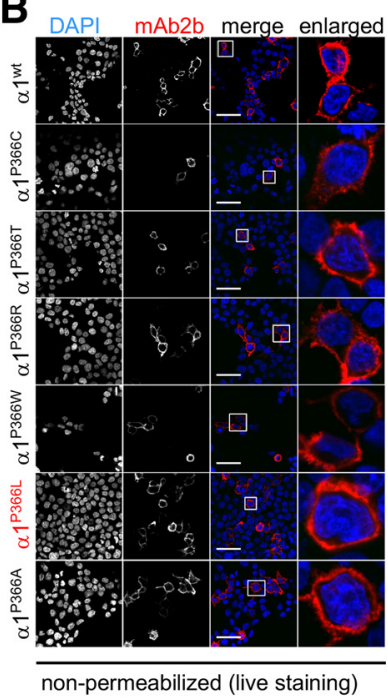

C
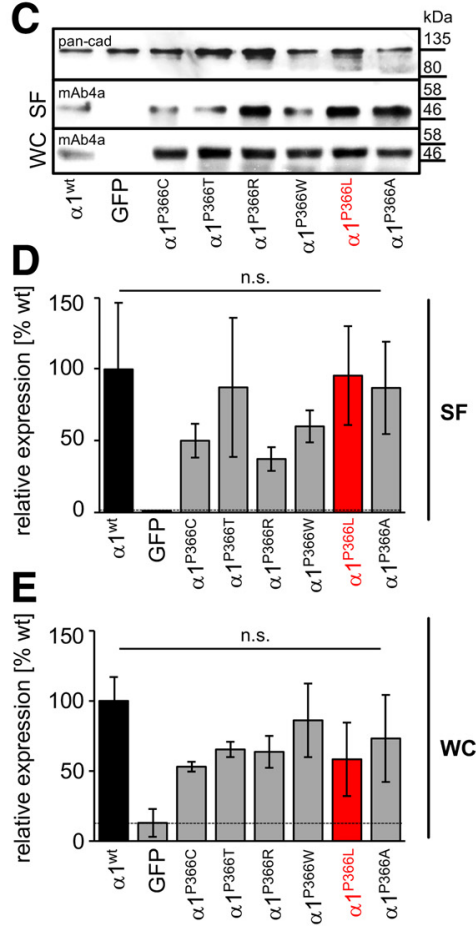

Figure 2. Expression of $\alpha 1^{\mathrm{P} 366}$ variants in transfected HEK293 cells shows no differences in subcellular expression patterns. $\boldsymbol{A}$, GlyR (red) was stained in permeabilized cells using the panGlyR antibody mAb4A. $\boldsymbol{B}$, Live staining of $\alpha 1$ variants at the cellular surface using the $\alpha 1$-specific antibody mAb2b. White squares represent the region enlarged in magnification column. Scale bar, $50 \mu \mathrm{m}$. DAPI staining is shown in blue. C, Comparison of whole-cell (WC) and surface (SF) receptor expression observed from transfected HEK293 cells. Cadherin (135 kDa) was stained as a membrane marker control. All receptor constructs carrying an amino acid substitution at position P366 were detected by the GlyR $\alpha$ antibody mAb4A at $48 \mathrm{kDa}$. $\boldsymbol{D}$, $\boldsymbol{E}$, Quantification of surface $(\boldsymbol{D})$ and whole-cell protein $(\boldsymbol{E})$ of GlyR $\alpha 1$ constructs mutated at position $\alpha 1^{\mathrm{P} 366}$ compared with $\alpha 1^{\mathrm{Wt}}$. Note that no differences in protein expression of GlyR $\alpha 1^{\mathrm{P} 366 \mathrm{~L}}$ (red bars) compared with $\alpha 1^{\text {wt }}$ (black bar) have been detected. Two-tailed $t$ test; n.S., nonsignificant; dotted line marks the background signal of GFP-transfected cells. All values shown are the mean \pm SEM.

structural information about the TM3-4 loop is available (Fig. $1 C)$. To investigate the consequences of the $\alpha 1^{\mathrm{P} 366 \mathrm{~L}}$ mutation at the molecular, cellular, and functional level, we generated a set of $\alpha 1$ point mutations. The generated GlyR $\alpha 1$ variants differing in side chain volume, size, and polarity $\left(\alpha 1^{\mathrm{P} 366 \mathrm{~L}}, \alpha 1^{\mathrm{P} 366 \mathrm{C}}, \alpha 1^{\mathrm{P} 366 \mathrm{R}}\right.$, $\alpha 1^{\mathrm{P} 366 \mathrm{~T}}, \alpha 1^{\mathrm{P} 366 \mathrm{~W}}$, and $\left.\alpha 1^{\mathrm{P} 366 \mathrm{~A}}\right)$. The corresponding $\alpha 1$ TM3-4 loop sequence ${ }^{364} \mathrm{NPPPAPSKSP}{ }^{373}$ not only contains the PXXPXR/K PPII helix structural element, but, additionally, displays a striking similarity with the corresponding GlyR $\beta$ subunit region $\left({ }^{435} \mathrm{KPPPAKP}{ }^{441}\right)$, which mediates the interaction with intracellular syndapin I. To investigate the role of this structural element as well as a possible syndapin I binding of GlyR $\alpha 1$, we generated specific GlyR $\alpha 1$ sequence ${ }^{364} \mathrm{NPPPAPSKSP}{ }^{373}$ mutants, including exhaustive proline-to-alanine and prolineto-leucine exchanges $\left(\alpha 1^{\mathrm{P} 373 \mathrm{~A}}, \alpha 1^{\mathrm{P} 1-4 \mathrm{~A}}, \alpha 1^{1-5 \mathrm{~A}}, \alpha 1^{\mathrm{P} 1-5 \mathrm{~L}}\right.$ with $\mathrm{P} 365=\mathrm{P} 1, \quad \mathrm{P} 366=\mathrm{P} 2, \quad \mathrm{P} 367=\mathrm{P} 3, \mathrm{P} 369=\mathrm{P} 4$, and $\mathrm{P} 373=\mathrm{P} 5$; Fig. 1D).

\section{Proline 366 has no impact on surface and whole-cell} expression levels of GlyR $\alpha 1$ protein

Previous in vitro studies on hyperekplexia mutants have demonstrated that other GlyR $\alpha 1$ TM3-4 loop variants affect GlyR trafficking and protein stability (Villmann et al., 2009; Chung et al., 2010). GlyR $\alpha 1$ constructs carrying an amino acid substitution at position 366 were analyzed for whole-cell receptor expression (cells were permeabilized and stained with pan- $\alpha$ antibody $\mathrm{mAb} 4 \mathrm{~A}$ ) and surface-expressed GlyR $\alpha 1$ (cells were unpermeabilized, live staining with $\alpha 1$-specific antibody mAb2b) in HEK293 cells. No obvious change in the GlyR $\alpha 1$ expression pattern was detected for any of the constructs tested (Fig. 2A,B). The surface expression of the same constructs was further quantified using surface biotinylation, which allows discrimination between whole-cell and surface GlyR $\alpha 1$ protein. Whole-cell expression of constructs $\alpha 1^{\mathrm{P} 366 \mathrm{~L}}, \alpha 1^{\mathrm{P} 366 \mathrm{C}}, \alpha 1^{\mathrm{P} 366 \mathrm{~A}}, \alpha 1^{\mathrm{P} 366 \mathrm{R}}$, and $\alpha 1^{\mathrm{P} 366 \mathrm{~W}}$ were comparable to wild-type $\alpha 1^{\text {wt }}(n=3)$ levels, indicating that side chain volume and polarity at this position have no influence on receptor trafficking and expression (Fig. 2C-E). The surface expression of all $\alpha 1^{\mathrm{P} 366 \mathrm{X}}$ constructs displayed no significant reduction compared with $\alpha 1^{\mathrm{wt}}$ ( $n=3$; Fig. $2 C, E$ ). Together, these results confirm that the patient mutation $\alpha 1^{\mathrm{P} 366 \mathrm{~L}}$ does not affect receptor biogenesis in vitro.

\section{GlyR $\alpha 1^{\text {P366L }}$ has minor effects on the physiological} properties of $\alpha \mathbf{l}$-containing GlyRs

To determine the functional consequences of $\alpha 1^{\mathrm{P} 366 \mathrm{~L}}, \alpha 1^{\mathrm{wt}}$, and mutated variants at position 366 or at the other proline positions within the sequence ${ }^{364}$ NPPPAPSKSP ${ }^{373}$ (Fig. 1D) were transiently expressed in HEK293 cells as homomeric GlyRs and investigated using whole-cell patch-clamp electrophysiology. Since the mature GlyR isoform at the synaptic sites in mammalian spinal cord and brainstem is expressed as a combination of $\alpha 1$ and $\beta$ subunits, we determined the influence of the $\alpha 1^{\mathrm{P} 366 \mathrm{~L}}$ mutation in homomeric $\alpha 1$ as well as heteromeric $\alpha 1 \beta$ configurations (Fig. $3 A$ ). A reduction in $I_{\max }$ suggesting a decrease in glycine efficacy was observed for homomeric $\alpha 1^{\mathrm{P} 366 \mathrm{~L}}$ and for heteromeric $\alpha 1^{\mathrm{P} 366 \mathrm{~L}} \beta$ receptors compared with $\alpha 1^{\mathrm{wt}} \beta$ (homomeric $\alpha 1^{\mathrm{P} 366 \mathrm{~L}}$ : $I_{\text {max }}, 64 \pm 9 \% ; n=21 ; t$ value $=2.277 ; \mathrm{df}=54 ;{ }^{\star} p=0.026$; heteromeric $\alpha 1^{\mathrm{P} 366 \mathrm{~L}} \beta: I_{\max }, 61 \pm 8 \% ; n=20 ; t$ value $=2.2229 ; \mathrm{df}=42$; ${ }^{*} p=0.0312$; Table 1 ). 

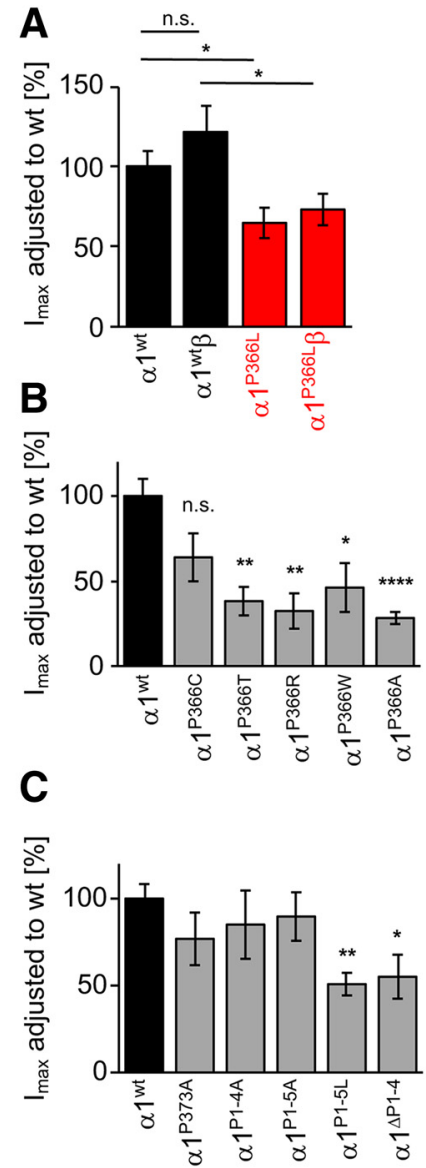
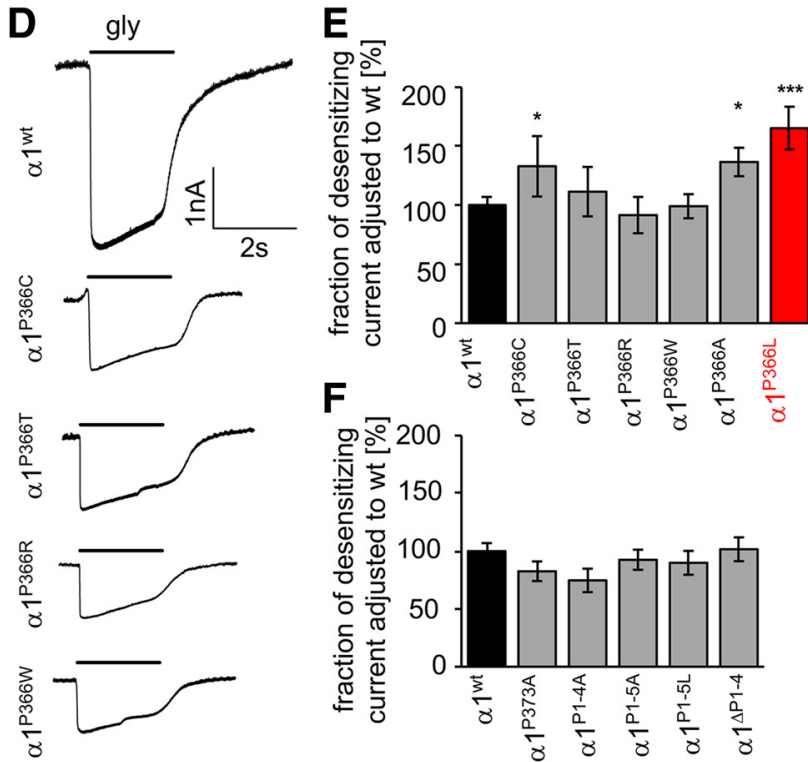

G
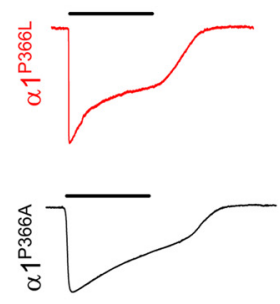

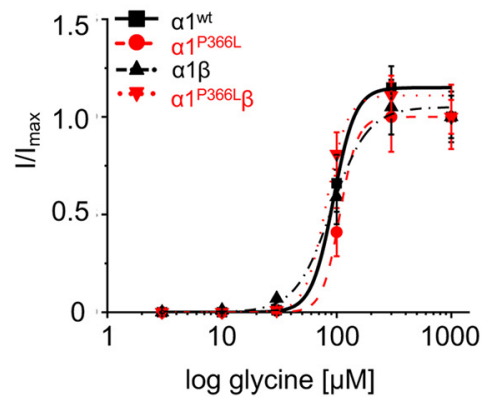

Figure 3. Mutations of residue P366 lead to reduced maximal chloride currents and changes in the desensitization kinetics of the GlyR $\alpha 1$. $\boldsymbol{A}$, Comparison of $I_{\text {max }}$ on application of 1 mm glycine between $\alpha 1^{\text {wt }}$ (black) and $\alpha 1^{\mathrm{P} 366 \mathrm{~L}}$ (red) in homomeric and heteromeric receptor configuration. $\boldsymbol{B}, I_{\max }$ values of GlyR $\alpha 1$ constructs mutated at position P366 compared with $\alpha 1^{\text {wt }}$ (Table 1). $C, I_{\max }$ values of $\alpha 1$ constructs with different proline mutations within the sequence ${ }^{364}$ NPPPAPSKSP ${ }^{373}$. D, Representative traces of glycine-activated $\alpha 1$ constructs used for the calculation of $I_{\max }$ and the analysis of desensitizing current fractions. $\boldsymbol{E}, \boldsymbol{F}$, Comparison of fractions of desensitization currents obtained from GlyR $\alpha 1$ constructs mutated at position P366 (E) or within the ${ }^{364}$ NPPPAPSKSP ${ }^{373}$ motif $(\boldsymbol{F})$. G, Dose-response relationship for homomeric $\left(\alpha 1^{\text {wt }}\right.$, black line; $\alpha 1^{\text {P366L }}$, red dashed line) and heteromeric $\left(\alpha 1^{\text {wt }} \beta\right.$, black dashed line; $\alpha 1^{\text {P366L }} \beta$, red dotted line). Glycine concentrations ranged from $3 \mu \mathrm{m}$ to $1 \mathrm{~mm} .{ }^{*} p<0.05,{ }^{* *} p<0.01,{ }^{* *} p<0.001,{ }^{* * *} p<0.0001$, n.s., nonsignificant. All values shown are the mean \pm SEM.

Table 1. Electrophysiological properties obtained from GlyR $\propto 1$ mutants

\begin{tabular}{|c|c|c|c|c|c|c|}
\hline Pass & $\begin{array}{l}\text { Number } \\
\text { of cells }\end{array}$ & $I_{\max }(\mathrm{nA})$ & $I_{\max }(\%$ from weight) & $\begin{array}{l}\text { Number } \\
\text { of cells }\end{array}$ & $\begin{array}{l}\text { Desensitizing } \\
\text { current fraction (\%) }\end{array}$ & $\begin{array}{l}\text { Desensitizing current } \\
\text { fraction ( } \% \text { from weight) }\end{array}$ \\
\hline$\alpha 1 \mathrm{wt}$ & 35 & $3.1 \pm 0.3$ & $100 \pm 10$ & 25 & $32 \pm 3$ & $100 \pm 7$ \\
\hline$\alpha 1 w t+\beta$ & 24 & $4.0 \pm 0.5$ & $121 \pm 17$ & n.d. & n.d. & n.d. \\
\hline$\alpha 1 \mathrm{P} 366 \mathrm{~L}$ & 21 & $2.0 \pm 0.3$ & $64 \pm 9$ & 15 & $53 \pm 6$ & $165 \pm 18$ \\
\hline$\alpha 1 \mathrm{P} 366 \mathrm{~L}+\beta$ & 20 & $2.4 \pm 0.3$ & $61 \pm 8^{\#}$ & n.d. & n.d. & n.d. \\
\hline$\alpha 1 \mathrm{P} 366 \mathrm{C}$ & 13 & $2.0 \pm 0.4$ & $64 \pm 14$ & 9 & $43 \pm 8$ & $133 \pm 26$ \\
\hline$\alpha 1 \mathrm{P} 366 \mathrm{~T}$ & 12 & $1.2 \pm 0.3$ & $38 \pm 8$ & 10 & $36 \pm 7$ & $111 \pm 21$ \\
\hline$\alpha 1 \mathrm{P} 366 \mathrm{R}$ & 12 & $1.0 \pm 0.3$ & $32 \pm 10$ & 10 & $30 \pm 5$ & $92 \pm 15$ \\
\hline$\alpha 1 \mathrm{P} 366 \mathrm{~W}$ & 12 & $1.4 \pm 0.4$ & $46 \pm 14$ & 11 & $32 \pm 3$ & $99 \pm 10$ \\
\hline$\alpha 1 \mathrm{P} 366 \mathrm{~A}$ & 17 & $0.9 \pm 0.1$ & $28 \pm 4$ & 17 & $44 \pm 4$ & $137 \pm 12$ \\
\hline$\alpha 1 \mathrm{P} 373 \mathrm{~A}$ & 9 & $1.8 \pm 0.4$ & $77 \pm 15^{\# \#}$ & 10 & $27 \pm 3$ & $82 \pm 9$ \\
\hline$\alpha 1^{\mathrm{P} 1-4 \mathrm{~A}}$ & 11 & $1.9 \pm 0.4$ & $85 \pm 20^{\# \#}$ & 11 & $24 \pm 3$ & $75 \pm 10$ \\
\hline$\alpha 1^{\mathrm{P1}-5 \mathrm{~A}}$ & 13 & $1.8 \pm 0.3$ & $90 \pm 14^{\# \#}$ & 13 & $30 \pm 3$ & $93 \pm 9$ \\
\hline$\alpha 1^{\mathrm{P} 1-5 \mathrm{~L}}$ & 26 & $1.6 \pm 0.2$ & $51 \pm 6^{\# \#}$ & 24 & $29 \pm 3$ & $90 \pm 10$ \\
\hline$\alpha 1 \Delta \mathrm{P} 1-4$ & 22 & $1.5 \pm 0.3$ & $55 \pm 13^{\# \#}$ & 21 & $33 \pm 3$ & $102 \pm 10$ \\
\hline
\end{tabular}

Data are the mean \pm SEM, unless otherwise indicated. n.d., Not determined.

${ }^{\#}$ Compared with $\alpha 1^{w t}+\beta{ }^{\text {; }}{ }^{\# \#}$ compared with $\alpha 1^{\text {wt }}$ from the same experiments.

With the exception of $\alpha 1^{\mathrm{P} 366 \mathrm{C}}(64 \pm 14 ; n=13$; $t$ value $=1.87$; $\mathrm{df}=46 ; p=0.067), \alpha 1^{\mathrm{P} 366 \mathrm{~T}}(38 \pm 8 \% ; n=12 ; t$ value $=3.214 ; \mathrm{df}=$ $\left.44 ;{ }^{* *} p=0.0024\right), \alpha 1^{\mathrm{P} 366 \mathrm{R}}(32 \pm 10 \% ; n=12 ; t$ value $=3.467$; $\left.\mathrm{df}=44 ;{ }^{*} p=0.0012\right), \alpha 1^{\mathrm{P} 366 \mathrm{AW}}(46 \pm 14 \% ; n=12 ; t$ value $=$
2.606; $\left.\mathrm{df}=44 ;{ }^{*} p=0.012\right)$, and $\alpha 1^{\mathrm{P} 366 \mathrm{~A}}(28 \pm 4 \% ; n=17 ; t$ value $\left.=4.590 ; \mathrm{df}=49 ;{ }^{* * * *} p<0.0001\right)$ exhibited significantly reduced maximum inward currents in response to saturating concentrations (1 mM) of glycine (Fig. 3B,D, Table 1). This points toward a 
A

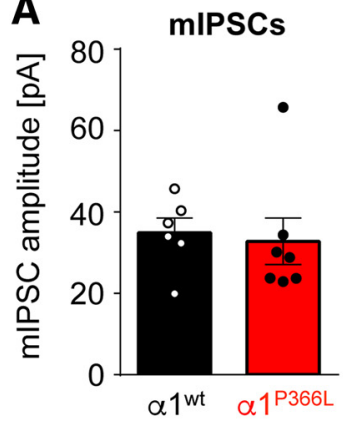

B

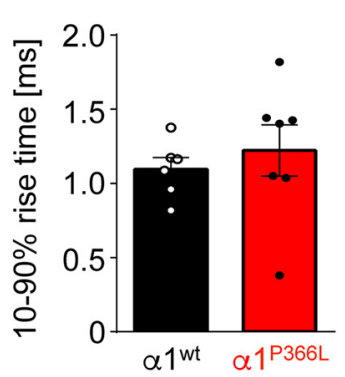

C

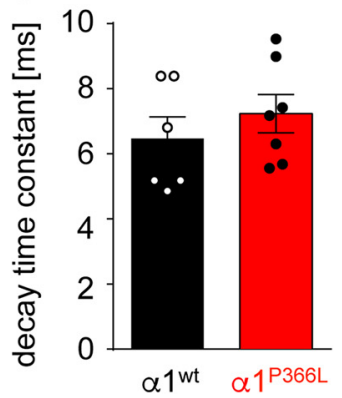

Figure 4. The P366L mutation does not alter mIPSCs. A-C, Properties of spontaneous mIPSCs mediated by the $\alpha 1^{\mathrm{P} 366 \mathrm{~L}}$ mutation. $\boldsymbol{A}-\boldsymbol{C}$, Comparison of the mean amplitude $(\boldsymbol{A})$, rise time $\left(10-90 \%\right.$; $(\boldsymbol{B})$, and decay time constants $(\boldsymbol{C})$ for $\alpha 1^{\text {wt }}$ and the mutant $\alpha 1^{\mathrm{P} 366 \mathrm{~L}}$. Recordings were performed from artificial synapses between spinal cord neurons and transfected HEK293 cells expressing the indicated GlyRs.

distinct influence of residue P366 on GlyR $\alpha 1$ glycine efficacy. According to surface expression analysis (Fig. 2), these observations were unlikely to result from reduced cell surface receptor expression. From all GlyR constructs with a modified PPII helix tested, the exchange of all proline residues within the sequence ${ }^{364}$ NPPPAPSKSP ${ }^{373}$ to leucines $\left(\alpha 1^{\mathrm{P} 1-5 \mathrm{~L}}\right)$ and deletion of four prolines $\left(\alpha 1^{\Delta \mathrm{P} 1-4}\right)$ led to significant reduction of glycine-gated currents $\left(\alpha 1^{\mathrm{P} 1-5 \mathrm{~L}}: 51 \pm 6 \%\right.$ compared with $\alpha 1^{\mathrm{wt}} ; n=26$; $F=4.091 ; \mathrm{df}=39 ;{ }^{*} p=0.016 ; \alpha 1^{\Delta \mathrm{P} 1-4}: 55 \pm 13 \%$ compared with $\alpha 1^{\mathrm{wt}} ; n=22 ; F=4.105 ; \mathrm{df}=37 ;{ }^{* *} p=0.0044$, respectively; Fig. $3 C)$. Notably, replacing these prolines within the putative PPII structure by alanines had no effect on $I_{\max }$ (Fig. $3 C$ ).

Variations in the GlyR $\alpha 1$ TM3-4 loop sequences have previously been shown to influence whole-cell desensitization (Breitinger et al., 2002; Papke and Grosman, 2014; Langlhofer et al., 2015). For that reason, we next investigated the desensitization behavior of homomeric $\alpha 1^{\mathrm{wt}}$ and $\alpha 1365-373$ proline variants. Current traces (Fig. $3 E$ ) were analyzed to compare the differences in their desensitization kinetics. In the presence of 1 mu glycine, a fraction of $32 \pm 3 \%$ of desensitizing inward currents was observed for $\alpha 1^{\text {wt }}(n=25$; Table 1$)$. This value was taken as a reference and set to $100 \%$ to compare desensitization kinetics with mutant GlyRs. Mutants $\alpha 1^{\text {P366C }}(133 \pm 26 \%$ desensitizing current fraction compared with $\alpha 1^{\mathrm{wt}} ; n=9 ; t$ value $=$ $\left.2.040 ; \mathrm{df}=32 ;{ }^{\star} p=0.049\right), \alpha 1^{\mathrm{P} 366 \mathrm{~A}}(136 \pm 12 \% ; n=17 ; t$ value $=$ 2.697; $\left.\mathrm{df}=42 ;{ }^{*} p=0.01\right)$ and $\alpha 1^{\mathrm{P} 366 \mathrm{~L}}$ generated GlyR $\alpha 1$ currents that desensitized more rapidly (Fig. $3 E$, Table 1 ) compared with $\alpha 1^{\mathrm{wt}}$. For $\alpha 1^{\mathrm{P} 366 \mathrm{~L}}$, the fraction of desensitizing currents was averaged to $165 \pm 18 \%\left(n=15 ; t\right.$ value $\left.=3.804 ; \mathrm{df}=38 ;{ }^{* *} p=0.0005\right)$ compared with $\alpha 1^{\mathrm{wt}}$, arguing for less chloride influx in the presence of extracellular glycine due to enhanced receptor desensitization. Mutating other prolines surrounding P366 $\left(\alpha 1^{\mathrm{P} 373 \mathrm{~L}}\right.$, $\left.\alpha 1^{\mathrm{P} 1-4 \mathrm{~L}}, \alpha 1^{\mathrm{P} 1-4 \mathrm{~A}}, \alpha 1^{\mathrm{P} 1-5 \mathrm{~L}}, \alpha 1^{\Delta \mathrm{P} 1-4}\right)$ had no significant influence on channel kinetics (Fig. $3 F$ ).

To determine the glycine $\mathrm{EC}_{50}$, concentration-response experiments were conducted in transfected cells (Fig. 3G). Homomeric $\alpha 1^{\mathrm{wt}}$ exhibited an $\mathrm{EC}_{50}$ of $94 \pm 11 \mu \mathrm{M}(n=7)$. This value was not significantly different from that for $\alpha 1^{\mathrm{P} 366 \mathrm{~L}}$ $(106 \pm 2 \mu \mathrm{M} ; n=8)$. Similarly, $\alpha 1^{\mathrm{P} 366 \mathrm{~L}} \beta \quad(81 \pm 17 \mu \mathrm{M} ; n=8)$ showed glycine $\mathrm{EC}_{50}$ values comparable to those of $\alpha 1^{\mathrm{wt}} \beta$ (90 $\pm 4 \mu \mathrm{M} ; n=9$; Fig. $3 G$ ). These results indicate that the P366L mutation does have an impact on GlyR $\alpha 1$ efficacy, but not on potency.

Using an artificial synapse model, recordings of spontaneous glycinergic synaptic currents mediated by $\alpha 1^{\mathrm{P} 366 \mathrm{~L}}$ GlyRs $(n=7)$ were compared with those mediated by $\alpha 1^{\text {wt }}$ GlyRs $(n=6)$. We

observed no significant differences in synaptic current amplitudes, rise times, or decay times (two-tailed $t$ test; amplitude: $t=0.5666, \mathrm{df}=9, p=0.58$; rise: $t=$ $0.6520, \mathrm{df}=9, p=0.53$; decay: $t=2.021$, $\mathrm{df}=9, p=0.074$; Fig. $4 A-C$ ).

\section{The intracellular PPII helix has no impact on extracellular domain movements during ion channel opening}

The observed lower net chloride flux for $\alpha 1^{\text {P366L }}$ compared with the $\alpha 1^{\text {wt }}$ could not be explained by reduced surface expression. Another possibility is that receptor gating dynamics have been altered by the P366L mutation. Glycineinduced dynamic changes in receptor configuration can be monitored using voltage-clamp fluorometry (VCF) techniques. By covalently attaching a fluorophore to the extracellular domain of the receptors, VCF enables the simultaneous recording of changes in current and fluorescence (Pless et al., 2007; Pless and Lynch, 2009). Following application of the ligand glycine, in addition to the observed chloride inward current a shift in fluorescence is observed, pointing to changes in molecule mobility. Two residues of GlyR $\alpha 1$ in the extracellular domain (N203 and R271; Fig. 5A) exhibit large changes in fluorescence in response to glycine application and thus have been determined as highly flexible in the process of receptor gating (Pless et al., 2007; Pless and Lynch, 2009). We constructed double mutants GlyR $\alpha 1^{\mathrm{N} 203 \mathrm{C} / \mathrm{P} 366 \mathrm{~L}}$ and $\alpha 1^{\mathrm{R} 271 \mathrm{C} / \mathrm{P} 366 \mathrm{~L}}$ in a vector suitable for the oocyte expression system. The application of saturating concentrations of glycine induced a chloride ion influx and changes in fluorescence $\left(I_{\max } ; \alpha 1^{\mathrm{N} 203 \mathrm{C}}: 3.6 \pm 0.7 \mu \mathrm{A}\right.$; $n=14 ; \alpha 1^{\mathrm{N} 203 \mathrm{C} / \mathrm{P} 366 \mathrm{~L}}: 2.1 \pm 0.6 \mu \mathrm{A} ; n=14 ;$ two-tailed unpaired $t$ test, $t=1.725, \mathrm{df}=27, p=0.09 ; \alpha 1^{\mathrm{R} 271 \mathrm{C}}: 1.3 \pm 0.5 \mu \mathrm{A} ; n=11$; $\alpha 1^{\mathrm{R} 271 \mathrm{C} / \mathrm{P} 366 \mathrm{~L}}: 1.8 \pm 0.5 \mu \mathrm{A} ; n=22 ; t=0.5876 ; \mathrm{df}=33, p=0.56$; changes in fluorescence, $\Delta F ; \alpha 1^{\mathrm{N} 203 \mathrm{C}}: 53 \pm 4 \% ; n=8 ; \alpha 1^{\mathrm{N} 203 \mathrm{C} /}$ P366L $: 43 \pm 8 \% ; n=13 ; t=0.912 ; \mathrm{df}=19 ; p=0.37 ; \alpha 1^{\mathrm{R} 271 \mathrm{C}}$ : $13 \pm 2 \% ; n=8 ; \alpha 1^{\mathrm{R} 271 \mathrm{C} / \mathrm{P} 366 \mathrm{~L}} ; 13 \pm 1 \% ; n=14 ; t=0.3674 ; \mathrm{df}=20$; $p=0.71$; Fig. $5 B-E$ ). There were no obvious differences between the $\alpha 1^{\mathrm{N} 203 \mathrm{C}}$ and $\alpha 1^{\mathrm{N} 203 \mathrm{C} / \mathrm{P} 366 \mathrm{~L}}$ or $\alpha 1^{\mathrm{R} 271 \mathrm{C}}$ and $\alpha 1^{\mathrm{R} 271 \mathrm{C} / \mathrm{P} 366 \mathrm{~L}}$, arguing that the integrity of the intracellular PPII helix does not affect extracellular conformational changes that can be probed through residues $\alpha 1^{\mathrm{N} 203 \mathrm{C}}$ and $\alpha 1^{\mathrm{R} 271 \mathrm{C}}$.

\section{GlyR $\alpha 1^{\text {P366L }}$ exhibited altered single-channel properties}

To further investigate functional changes of the $\alpha 1^{\mathrm{P} 366 \mathrm{~L}}$ mutation, we analyzed currents mediated by single-receptor molecules focusing on heteromeric $\alpha 1^{\mathrm{P} 366 \mathrm{~L}} \beta$ receptors. Single-channel recordings were used to determine the presence of spontaneous activity in the absence of glycine, the incidence of active periods of different amplitude levels, the $I-V$ relationship, and conductance.

Our first experiments were aimed at determining whether the $\alpha 1^{\mathrm{P} 366 \mathrm{~L}}$ mutation gave rise to spontaneous activity in heteromeric GlyRs. In the absence of glycine, outside-out patches expressing the GlyR $\alpha 1^{\mathrm{P} 366 \mathrm{~L}} \beta$ in contrast to $\alpha 1^{\mathrm{wt}} \beta$ opened sporadically over a recording period of 5-10 min. Single-channel opening times were brief and lasting $\sim 2-3 \mathrm{~ms}(n=3$; Fig. $6 A, B)$. This level of activity was more frequent than $\alpha 1^{\text {wt }}$ receptors under the same recording conditions (Fig. 6A), but was less frequent than another spontaneously active $\alpha 1$ mutation that gives 

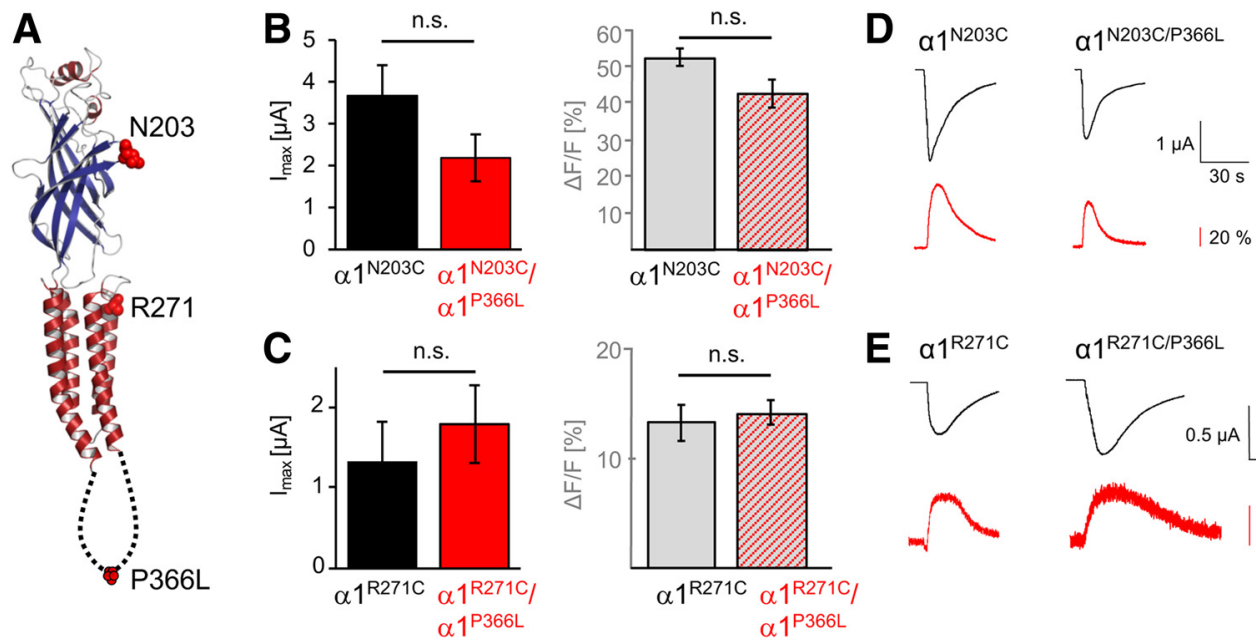

E $\alpha 1^{\mathrm{R} 271 \mathrm{C}}$

$\alpha 1^{\mathrm{R} 271 \mathrm{C} / \mathrm{P} 366 \mathrm{~L}}$

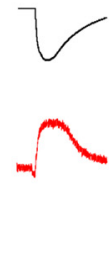

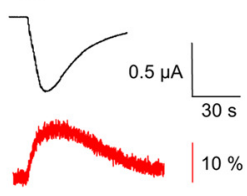

Figure 5. The intracellular mutation $\alpha 1 \mathrm{P}^{366 \mathrm{~L}}$ of the GlyR has not impact on changes of receptor conformation at the extracellular site. $\boldsymbol{A}$, Single GlyR $\alpha 1$ subunit. Marked are residues N203,

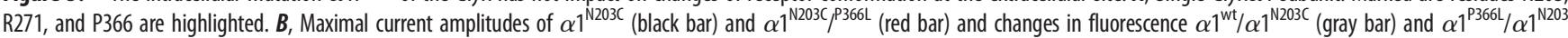
(red/gray striped; right graph). C, Same as in $\boldsymbol{B}$ but comparison of $\alpha 1^{\text {R271C }}$ and $\alpha 1^{\text {R271C/P366C }}$. D, Representative traces of currents (black traces) and changes in fluorescence (red traces) induced

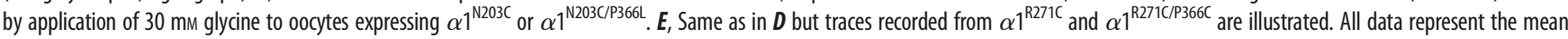
\pm SEM. n.s., nonsignificant.

rise to hyperekplexia, $\alpha 1^{\mathrm{Q} 226 \mathrm{E}}$ (paired Holm-Sidak test; $\alpha 1^{\mathrm{wt}} \beta$ compared with $\alpha 1^{\mathrm{P} 366 \mathrm{~L}} \beta: t=3.144, p=0.02 ; \alpha 1^{\mathrm{P} 366 \mathrm{~L}} \beta$ compared with $\alpha 1^{\mathrm{Q} 226 \mathrm{E}} \beta: t=5.363, p=0.003 ; \alpha 1^{\mathrm{wt}} \beta$ compared with $\alpha 1^{\mathrm{Q} 226 \mathrm{E}} \beta: t=8.507, p<0.001$; Fig. $6 C$; Bode and Lynch, 2013). The rank order of opening probability was $(n=3) \sim 0,<0.01$, and $<0.03$ for $\alpha 1 \beta^{\mathrm{wt}}, \alpha 1^{\mathrm{P} 36 \mathrm{~L}} \beta$ GlyR, and $\alpha 1^{\mathrm{Q} 226 \mathrm{E}} \beta$ GlyR, respectively (Scott et al., 2015). The more frequent spontaneous activity of $\alpha 1^{\mathrm{P} 366 \mathrm{~L}} \beta$ is probably not due to differences in numbers of channels in each patch as the surface expression of $\alpha 1^{\mathrm{P} 366 \mathrm{~L}} \beta$ was not changed compared with $\alpha 1 \beta^{\mathrm{wt}}$ receptors. Activated $\alpha 1 \beta$ GlyRs form discrete clusters of activity separated by long nonconducting periods that correspond to desensitization (Fig. 7A). Two main amplitude levels were apparent (Fig. $7 A$, top). The most frequent amplitude was $3.3 \pm 0.1 \mathrm{pA}$ $(-70 \mathrm{mV}, n=5)$, which constituted $>95 \%$ of the activity. A smaller amplitude $(2.4 \pm 0.1 \mathrm{pA})$ was also observed, but this was rare and usually occurred as a transition within a cluster (Fig. $7 A$, bottom). The $I-V$ plot for $\alpha 1^{\mathrm{wt}} \beta$ receptors was near linear, producing a reversal potential of $5 \mathrm{mV}$ (Fig. $7 B$ ). This enabled us to estimate the conductance of the main level according to Equation 2, which was $41.4 \mathrm{pS}$ at $-70 \mathrm{mV}$.

Single-channel activations of $\alpha 1^{\mathrm{P} 366 \mathrm{~L}} \beta$ GlyRs also occurred in discrete clusters when exposed to $100 \mu \mathrm{M}$ glycine (Fig. $7 C$, top). Three main amplitude levels were apparent, the largest one being $3.0 \pm 0.6 \mathrm{pA}$ (at $-70 \mathrm{mV}, n=6$ ). This amplitude was the most frequent, constituting $75 \pm 4 \%$ of the activity. The other two levels were less frequent, being $17 \pm 3 \%(2.1 \pm 0.1 \mathrm{pA}, n=5)$ and $8 \pm 2 \%(1.0 \pm 0.1 \mathrm{pA}, n=5$; Fig. $7 C$, bottom $)$ of the overall activity. The $I-V$ for the mutant receptor was also near linear over the voltage range tested and reversed at $+5 \mathrm{mV}$ (Fig. $7 D$ ). The corresponding conductance levels for the mutant receptors at $-70 \mathrm{mV}$ were $37.6,26.3$, and $12.5 \mathrm{pS}$, respectively. A direct comparison of single-channel conductance shows a reduction to $\sim 80 \%$ for $\alpha 1^{\mathrm{P} 366 \mathrm{~L}} \beta$ receptors compared with the $\alpha 1^{\mathrm{wt}} \beta$ control (two-tailed $t$ test: $t=-3.238, \mathrm{df}=9, p=0.0102$; Fig. $7 E$ ).

\section{GlyR $\alpha 1^{\text {P366L }}$ harbors a syndapin I binding site which encompasses P366}

The spontaneous opening events of $\alpha 1^{\mathrm{P} 366 \mathrm{~L}} \beta$ identified in single-channel recordings were less frequent than in $\alpha 1^{\mathrm{Q} 226 \mathrm{E}} \beta$
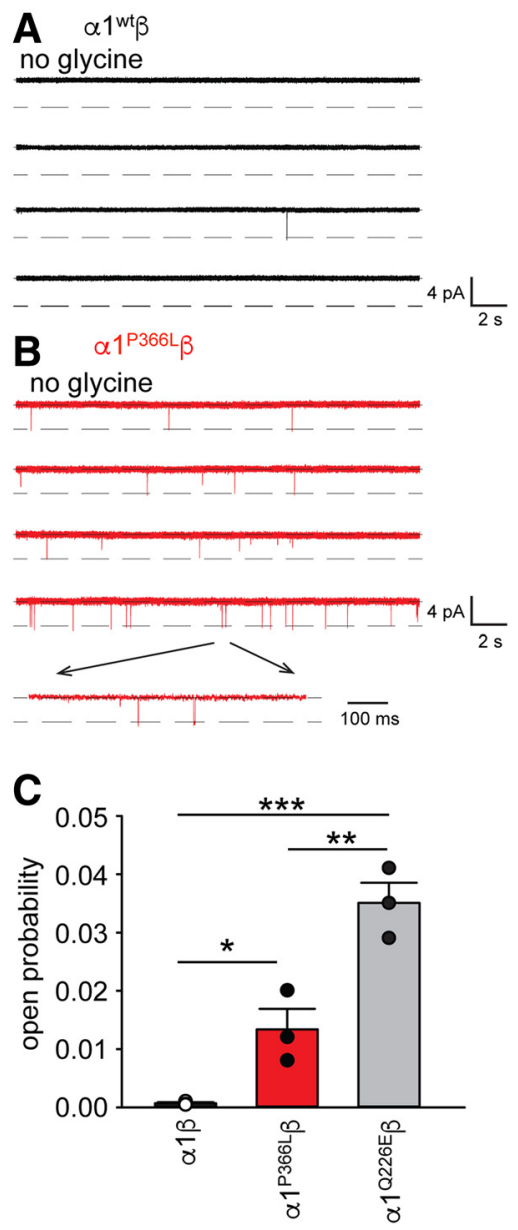

Figure 6. Spontaneous opening events in the absence of extracellular glycine. $\boldsymbol{A}, \boldsymbol{B}$, Single-channel recordings of heteromeric $\alpha 1^{\mathrm{Wt}} \beta$ GlyRs $(\boldsymbol{A})$ compared with $\alpha 1^{\mathrm{P3} 66 \mathrm{~L}} \beta(\boldsymbol{B})$ to investigate the spontaneous opening activity in the absence of glycine. Four independent traces for each condition are shown (black, $\alpha 1^{\mathrm{wt}} \beta$; red, $\alpha 1^{\text {P366L }} \beta$ ). C, Quantification of spontaneous open probabilities. The mutation $\alpha 1^{2226 \mathrm{E}}$ was also analyzed since spontaneous openings for this mutant have been shown before (Bode et al., 2013). Statistical significance refers to ${ }^{* *} p<0.001,{ }^{* *} p<0.01$, and ${ }^{*} p<0.05$. 
A

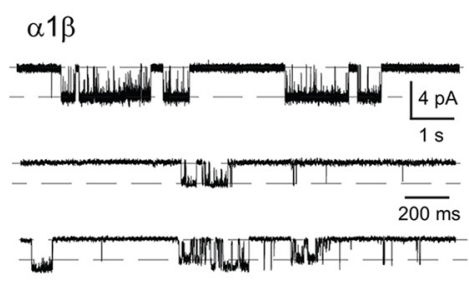

C

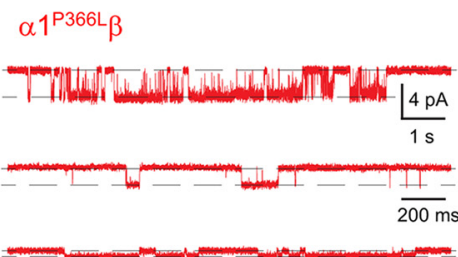

B

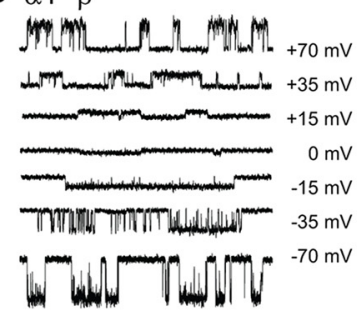

D

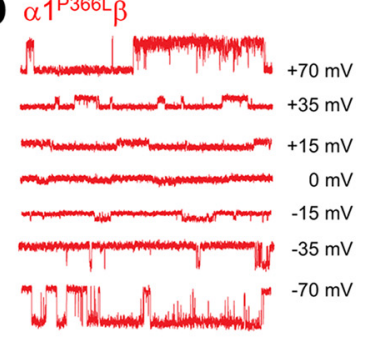

$\mathbf{E}$
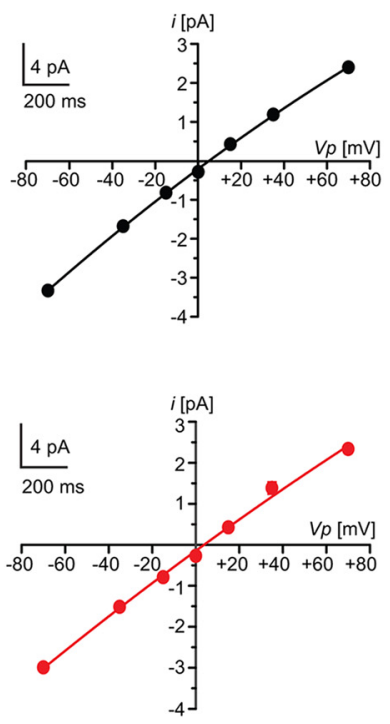

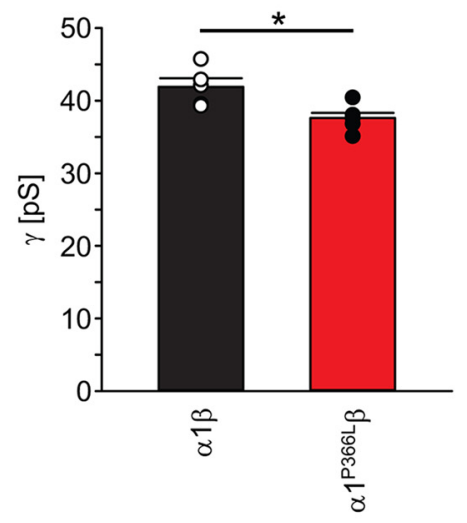

Figure 7. Proline 366 changes the unitary conductance. $A$, Single-channel activation clusters in a patch expressing at least three $\alpha 1^{\text {wt }} \beta$ GlyRs in the presence of $100 \mu \mathrm{m}$ glycine. The most common (>95\%) amplitude level was $3.3 \mathrm{pA}$ (top). There was also a smaller amplitude of " $2.4 \mathrm{pA}$ ". Traces are from the same patch, but different sections of the recording. $\boldsymbol{B}$, Sample recordings of single-channel activity of $\alpha 1^{\mathrm{wt}} \beta$ at the indicated voltages and the accompanying group $I-V(n=5)$. The $I-V$ was used to calculate a conductance of $41.4 \mathrm{pS}$. $C$, Single-channel activations of $\alpha 1^{\mathrm{P} 366 \mathrm{~L}} \beta$ in the presence of $100 \mu \mathrm{m}$ glycine. This channel opened to the following three levels: $3.0 \mathrm{pA}$ (top trace), $2.1 \mathrm{pA}$ (middle trace), and 1.0 pA (bottom trace). Activations to the largest level represented $75 \%$ of the overall activity. The top two traces are from the same patch, and the lower is from a different patch. Note, the middle and lower traces in $\boldsymbol{A}$ and $\boldsymbol{C}$ have a different time scale to show subconductance levels at higher temporal solution that were less frequent. $\boldsymbol{D}$, Sample recordings of single-channel activity of mutant $\alpha 1^{\mathrm{P} 366 \mathrm{~L}} \beta$ at the indicated voltages and the accompanying group $I-V(n=6)$. The $I-V$ was used to calculate the corresponding conductances of 37.6, 26.3, and $12.5 \mathrm{pS}$. $E$, Single-channel conductance of $\alpha 1^{\text {wt }} \beta$ and $\alpha 1^{\mathrm{P} 366 \mathrm{~L}} \beta$. Significance values, ${ }^{*} p=0.0102$.

(Scott et al., 2015), suggesting that tonic activity alone might not explain the hyperekplexia phenotype observed. There might be other structural impacts of GlyR $\alpha 1^{\mathrm{P} 366 \mathrm{~L}}$ in addition to the specified functional changes. Residues within the TM3-4 loop of GlyRs are involved in interactions with intracellular binding partners or are responsible for post-translational modifications of the GlyR (Langlhofer and Villmann, 2016). GlyR $\beta$ residues ${ }^{398}$ FSIVGSLPRDFELS ${ }^{411}$ mediate direct binding of gephyrin (Maric et al., 2014, 2017). Furthermore, the GlyR $\beta$ sequence $\left({ }^{433}\right.$ NKKPPPAKPVIPTAA $\left.{ }^{447}\right)$ harbors a syndapin I binding site (Del Pino et al., 2014). Strikingly, the syndapin binding motif within the corresponding GlyR $\alpha 1$ region ${ }^{364} \mathrm{NPPPAPSKSP}{ }^{373}$ (Fig. 8A) contains the hyperekplexia mutation $\alpha 1^{\mathrm{P} 366 \mathrm{~L}}$ studied here (Fig. $1 B$ ). We therefore investigated whether GlyR $\alpha 1$ also interacts with syndapin I. Syndapin I recognizes class I and II poly-proline-rich motifs (Teyra et al., 2017; Goretzki et al., 2018). The GlyR $\beta$ sequence $\left({ }^{433}\right.$ NKKPPPAKPVIPTAA $\left.{ }^{447}\right)$ as well as the corresponding GlyR $\alpha 1$ region, with and without the hyperekplexia mutation studied here, were probed together with other reported syndapin I binding proteins (other known $\mathrm{SH} 3$ binding peptides containing class I and class II PxxP motifs) in microarray format for direct binding to syndapin I. The peptide NNNNTTNPPPAPSKS (GlyR $\alpha 1$ Mus musculus) was clearly bound to GST-syndapin I, as reported by syndapin I-HRPcoupled secondary antibody chemiluminescence (Fig. 8B). Introducing the $\alpha 1^{\mathrm{P} 366 \mathrm{~L}}$ or $\alpha 1^{\mathrm{P} 366 \mathrm{~A}}$ mutations into the same peptide significantly reduced syndapin I binding (two-tailed unpaired $t$ test: $\alpha 1^{\text {wt }}$ peptide NNNNTTNPPPAPSKS compared with $\alpha 1^{\mathrm{P} 366 \mathrm{~L}}$ NNNNTTNPLPAPSKS: $t=107, \mathrm{df}=4,{ }^{* * * *} p<$ $0.0001 ; \alpha 1$ wt peptide compared with $\alpha 1^{\text {P366A }}$ NNNNTT NPAPAPSKS: $t=167, \mathrm{df}=4,{ }^{* * * *} p<0.0001$; Fig. $8 B$ ).

The relative intensities of the peptide microarray binding signals validate the previously identified GlyR $\beta$ fragment as a high-affinity syndapin I interactor and at the same time indicate robust binding of the corresponding GlyR $\alpha 1$ region (Fig. $8 A, B$ ). Next, we wanted to further validate the in vitro discovered GlyR $\alpha 1 /$ syndapin I in ex vivo context. In the cell, binding of the native syndapin I may be further modulated by post-translational modifications and the presence of additional allosteric or directly competing endogenous ligands. Therefore, we used label-free quantitative MS/MS to explore the binding of syndapin I to the mapped GlyR $\beta$ and $\alpha 1$ regions as well as the P366L mutated $\alpha 1$ region in the context of their complete interactome. In label-free quantitative MS/MS, protein intensities (summed intensities of identified tryptic peptides of the corresponding protein) are compared among different LC-MS/MS runs.

First, we incubated whole-brain lysates from adult C57BL/6 mice (male) with resin-bound peptides corresponding to either $\alpha 1^{\text {wt }}$ or the $\alpha 1^{\mathrm{P} 366 \mathrm{~L}}$ mutation or the corresponding GlyR $\beta$ region. Protein interactors from the lysate were eluted, digested, and identified through nanoLC-MS/MS (Fig. 8C). Mass spectrometric analysis revealed a clear enrichment of syndapin I in the interactome of GlyR subunit fragments $\left(\alpha 1^{\text {wt }}{ }^{362}\right.$ TTNPPP APSKSPC $^{374}, \alpha 1^{\text {P366L }}{ }^{362}$ TTNPLPAPSKSPC ${ }^{374}$, and GlyR $\beta$ ${ }^{433}$ NKKPPPAKPVIPC ${ }^{445}$; Fig. $8 C$ ). Beyond syndapin I, the analysis also revealed enhanced binding of gephyrin, and endophilin (Fig. 8C), and the known interactor syndapin II to the GlyR $\beta$ fragment over the $\alpha 1$ fragment. We also used the label-free quantitative MS/MS to analyze and compare the pulldowns of $\alpha 1^{\mathrm{wt}}$ versus $\alpha 1^{\mathrm{P} 366 \mathrm{~L}}$. Both fragments enriched syndapin I, but no significant change in the extent of enrichment could be resolved on mutation (Fig. 8C).

To further confirm the protein-protein interaction between the GlyR $\alpha 1$ subunit and syndapin I, we performed GST pulldown assays (Fig. 9A). GlyR $\alpha 1$ was successfully pulled down by GST-sdpI ${ }^{\text {SH3 }}$, but not GST alone. Moreover, transfected HEK293 
A

\begin{tabular}{|c|c|c|}
\hline Name & Sequence & $\begin{array}{c}\text { Binding } \\
(0 \text { to } 1)\end{array}$ \\
\hline Class I & $-------+\mathbf{x} \times \mathrm{P} \times \mathbf{x} \times \mathrm{P} \mathbf{x}-----$ & \\
\hline Class II & $---------\mathbf{x} \mathrm{P} \mathbf{x} \mathbf{x} \mathrm{P} \mathbf{x}+----$ & \\
\hline sos1 & ---DEVPVPPPVPPRRRP-- & 0.8 \\
\hline SHANK2 & ----TARKKAPPPPKRAPT- & 0.9 \\
\hline GlyR $\beta$ & KPQAKNKKPPPAKPV----- & 0.8 \\
\hline GlyR $\beta$ & $-----N K K P P P A K P V I P T A A$ & 0.8 \\
\hline GlyR a1 & --NNNNTTNPP PAPSKS--- & 0.4 \\
\hline GlyR a $1^{P 366 L}$ & --NNNNTTNPLPAPSKS-- - & 0 \\
\hline
\end{tabular}

B

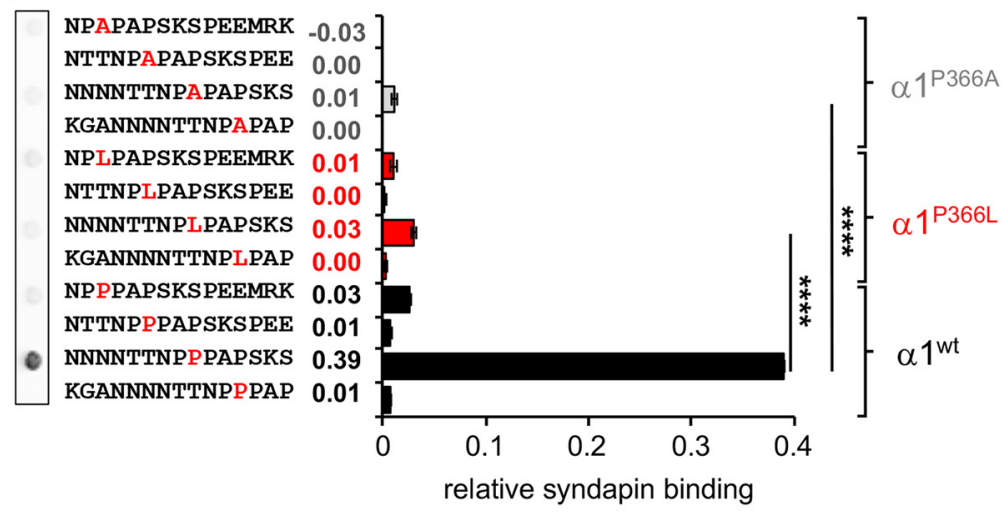

C
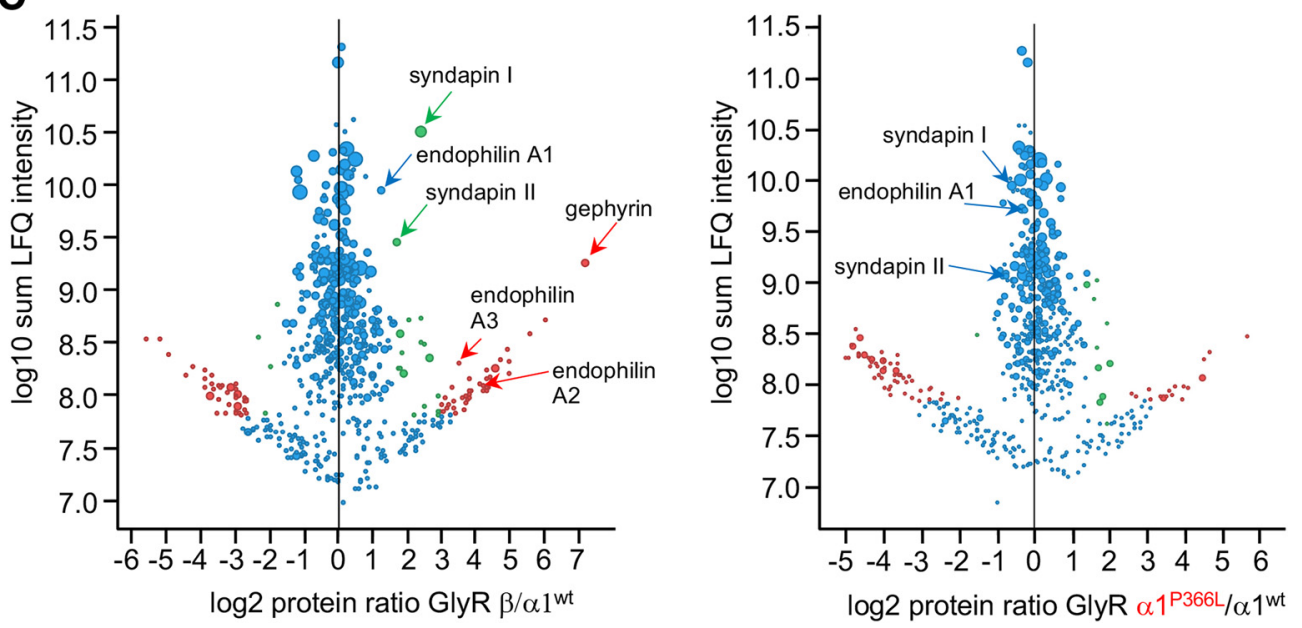

Figure 8. Identification of short GlyR $\alpha 1$-derived peptides as syndapin I binding probes. $\boldsymbol{A}, \boldsymbol{B}$, Sequence alignment of known syndapin I binding partners [GlyR $\beta$, SOS, and SHANK2; SOS1, son of sevenless homolog 1; SHANK2, SH3 and multiple ankyrin repeat domains protein 2-like (or PROSAP1); $A$ ] with corresponding binding intensities determined with the GST-syndapin I array (B). Syndapin I recognizes class I and II poly-proline-rich motifs (Teyra et al., 2017; Goretzki et al., 2018). Residues that satisfy the requirements of these recognition motifs are colored blue (charged basic), orange (proline), and red (cis-proline). The corresponding GlyR $\alpha 1$ sequences of the wild-type $\alpha 1^{\text {wt }}$ and the mutant $\alpha 1^{\text {P366L }}$ are shown (lower two lines). B, Peptide array-based alanine and leucine scan of the syndapin I binding site within the GlyR $\alpha 1$ subunit. Other known SH3 binding peptides containing class I and class II PxxP motifs were added as control peptides for the array (data not shown). Red residues refer to position 366 of the mature peptide. Syndapin I binding to peptides was detected by chemiluminescence of syndapin I-conjugated HRP. Shown are the relative averaged intensities of the detected syndapin spots of three peptide sets together with their SDs (error bars). Notably, a P366L or P366A mutation in the peptide ${ }^{358}$ NNNNTTNPPPAPSKS ${ }^{373}$ almost abolished binding to syndapin I $\left.{ }^{* * * *} p<0.0001\right)$. C, Quantitative mass spectrometric analyses of pulldowns with the corresponding peptides derived from $\alpha 1^{\text {wt }}\left({ }^{362}\right.$ TTNPPPAPSKSPP $\left.{ }^{374}\right), \alpha 7^{3366 L}\left({ }^{362}\right.$ TTNPLPAPSKSP $\left.^{374}\right)$, and GlyR $\beta\left({ }^{433} \mathrm{NKKPPPAKPVIPC}^{445}\right)$ subunits. Scatter plots show log2-transformed protein ratios (left graph, enrichment of pulldown using the GlyR $\beta$ peptide compared with pulldown using the $\alpha 1^{\text {wt }}$ peptide; right graph, enrichment of pulldown using GlyR $\alpha 1^{\text {P366L }}$ peptide compared with $\alpha 1^{\text {wt }}$ peptide). Proteins that are similarly abundant in both eluates are close to zero $\log 2(1)=0$ versus summed $\log 10$ LFQ protein intensities (highly abundant proteins show up at larger values). Significantly enriched proteins are classified as highly significant (red) and significant (green); proteins not enriched are shown in blue. The sizes of the dots correlate with the number of identified peptides.

cells with $\alpha 1$ or $\alpha 1^{\mathrm{P} 366 \mathrm{~L}}$ together with either syndapin I-eGFP (fusion protein of syndapin I and eGFP; $80 \mathrm{kDa}$ ) or syndapin IeGFP lacking the SH3 domain (sdpI ${ }^{\Delta \mathrm{SH} 3}$ ) were used for immunoprecipitation. The input images show the slight reduction in molecular weight of syndapin I lacking the $\mathrm{SH}_{3}$ domain compared with full-length syndapin I (Fig. 9B, top). The monoclonal antibody mAb2B successfully precipitated the GlyR [Fig. 9B, bottom (with lower image representing the precipitation control)]. Syndapin I-eGFP was coprecipitated together with the heteromeric $\alpha 1 \beta$ complexes and $\alpha 1^{\mathrm{P} 366 \mathrm{~L}} \beta$ but also with $\alpha 1$ and the mutated $\alpha 1$ variant $\alpha 1^{\mathrm{P} 366 \mathrm{~L}}$ when expressed alone. Additionally, syndapin I coprecipitation was almost abolished when syndapin 


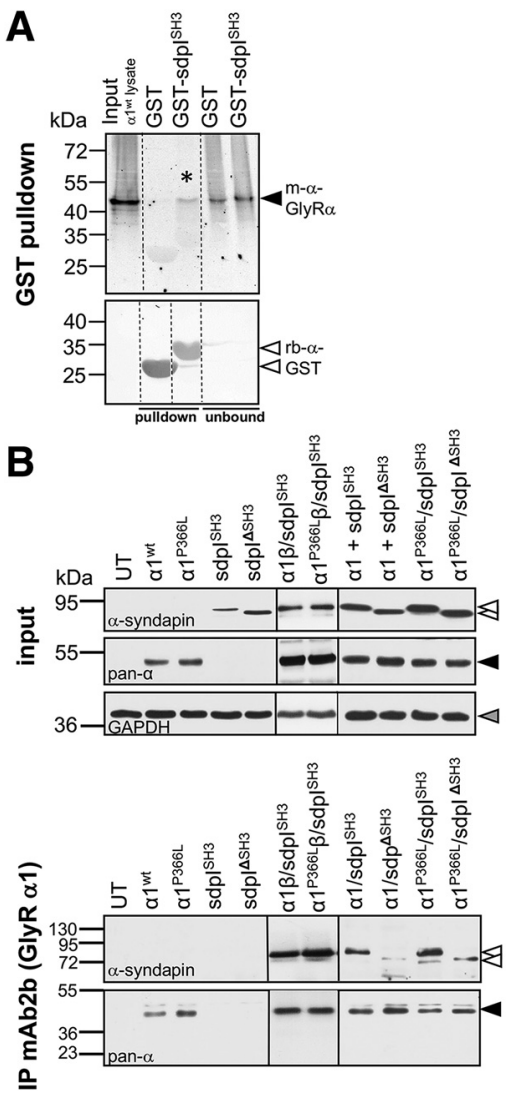

Figure 9. The GlyR $\alpha 1$ subunit interacts with syndapin I. A, Pulldown of the GlyR $\alpha 1$ wildtype subunit using GST-syndapin I SH3 domain (GST-sdpl ${ }^{\text {SH3 }}$ ). Lysates from HEK293 cells transfected with GlyR $\alpha 1^{\text {wt }}$ were incubated with either GST alone or GST-tagged syndapin I $\mathrm{SH} 3$ domain (GST-sdpl ${ }^{\mathrm{SH} 3}$ ). Aliquots of starting material (Input), unbound material (unbound), and precipitated proteins (pulldown) were analyzed for coprecipitated GlyR $\alpha 1^{\mathrm{wt}}$ (m- $\alpha$-GlyR $\alpha$ ) or GST (rb- $\alpha$-GST). Note that GlyR $\alpha{ }^{\text {wt }}$ was successfully pulled down by GSTsdpl ${ }^{\mathrm{SH} 3}$, but not by GST alone (marked by an asterisk, ${ }^{*}$ ). $\boldsymbol{B}$, Immunoprecipitation of syndapin I with and without the $\mathrm{SH} 3$ domain (sdpl ${ }^{\mathrm{SH} 3}$ and $\mathrm{sdpl}^{\mathrm{S}^{\mathrm{SH}} 3}$ ) together with GlyR $\alpha$ variants $\left(\alpha 1^{\text {wt }}\right.$ and $\left.\alpha 1^{\text {P366L }}\right)$ with and without the $\beta$ subunit. Input from transfected HEK293 cells are shown. Top, Input samples were stained against syndapin I, GlyR (mAb4a $=$ pan- $\alpha)$, or GAPDH (as housekeeping control protein). UT refers to untransfected cells. Bottom, Immunoprecipitation was performed using the GlyR $\alpha 1$-specific antibody mAb2b. Precipitated syndapin I (sdpl) is demonstrated in the top panel. Both GlyR $\alpha 1^{\text {wt }}$ and GlyR $\alpha 1^{\text {P366L }}$ are able to precipitate $s \mathrm{dpl}{ }^{\mathrm{SH} 3}$ and $\mathrm{sdpl}{ }^{\Delta \mathrm{SH} 3}$, however, with less intensity. The bottom panel shows the precipitation control of the GlyR (stained by mAb4a $=$ pan- $\alpha$ ).

I lacked the SH3 domain (Fig. 9B). Together, our data reveal binding of syndapin I to the mutated region within GlyR $\alpha 1$, indicating an interaction that so far has been attributed only to the GlyR $\beta$ subunit. The position of the mutation in the syndapin I binding motif suggests interference with syndapin binding. Direct interference of $\alpha 1^{\mathrm{P} 366 \mathrm{~L}}$ with syndapin binding can be resolved in vitro using the recombinant protein but not based on lysates containing the endogenous protein.

\section{Interaction between syndapin I and the $\alpha 1^{\mathrm{P} 366 \mathrm{~L}}$ mutant redistributes syndapin $I$ to the cell soma}

Our proteomic data demonstrate that syndapin I interacts with the SH3 consensus sequence of the GlyR $\alpha 1$ TM3-4 loop and that proline at position 366 contributes to this interaction. We speculated that mutant binding of syndapin I might affect normal syndapin I function in receptor trafficking and localization. Therefore, we explored the neuronal distribution of syndapin I in the presence of either $\alpha 1$ or $\alpha 1^{\mathrm{P} 366 \mathrm{~L}}$. Specifically, we stained endogenous neuronal syndapin I in virally infected primary

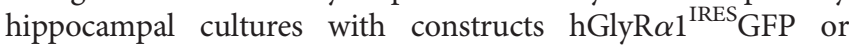
hGlyR $\alpha 1^{\text {P366L-IRES }}$ GFP, driving the low expression of either $\alpha 1$ or $\alpha 1^{\mathrm{P} 366 \mathrm{~L}}$ (Fig. 10A). Cells were stained after infection for surface GlyR $\alpha 1$ and whole-cell syndapin I at DIV14 $(n=3$; Fig. $10 B-D)$. Uninfected hippocampal neurons lacked $\alpha 1$ expression (Fig. 10D). Strikingly, we observed a strong increase in syndapin I signal intensity in the soma of cells expressing the mutant $\alpha 1^{\mathrm{P} 366 \mathrm{~L}}$ compared with $\alpha 1^{\mathrm{wt}}$ and uninfected cells (four to seven $z$-stacks were used for analysis, with a two-tailed $t$ test: $t=2.327$, $\mathrm{df}=9,{ }^{*} p=0.045$; Fig. 10E) that was accompanied by a decrease in the syndapin I signal intensity observed in neurites of $\alpha 1^{\mathrm{P} 366 \mathrm{~L}}$ infected cells $(t=2.045, \mathrm{df}=9, p=0.07)$. This result points out that $\alpha 1^{\mathrm{P} 366 \mathrm{~L}}$ specifically alters endogenous syndapin I distribution by accumulating syndapin in the cell soma.

\section{Discussion}

In this study, we identified a pattern of glycinergic dysfunction caused by the novel dominant startle disease mutation P366L, which is localized in the intracellular TM3-4 loop of the GlyR $\alpha 1$ subunit. Using this mutant, we uncovered a contribution of the $\alpha 1$ subunit to binding of the intracellular protein syndapin I, a function that has previously been previously assigned to the GlyR $\beta$ subunit only. Members of the syndapin family are SH3 domain-containing proteins involved in membrane protein trafficking, regulation, and interaction with actin cytoskeletal effectors (Qualmann and Kelly, 2000; Kessels and Qualmann, 2004; Dharmalingam et al., 2009; Koch et al., 2011; Schwintzer et al., 2011). The patient mutation $\alpha 1^{\mathrm{P} 366 \mathrm{~L}}$ is localized in a poly-proline-rich region forming a PPII helix in the GlyR $\alpha 1$ intracellular TM3-4 loop able to interact with the SH3-domain of syndapin I.

Most GlyR $\alpha 1$ hyperekplexia mutations $\left(\alpha 1^{\mathrm{R} 316 \mathrm{X}}, \alpha 1^{\mathrm{A} 384 \mathrm{P}}\right.$, $\alpha 1^{\mathrm{D} 388 \mathrm{~A}}$, and $\left.\alpha 1^{\mathrm{R} 392 \mathrm{H}}\right)$ in the TM3-4 loop exhibit a compound heterozygous mode of inheritance. Mutant $\alpha 1^{\mathrm{E} 375 \mathrm{X}}$ represents a recessive mutation, and $\alpha 1^{\mathrm{G} 342 \mathrm{~S}}$ is the only dominant inherited hyperekplexia mutation but with incomplete penetrance (Bode and Lynch, 2014). Recessive mutations have been shown to interfere with surface membrane integration of the GlyRs, whereas dominant mutations affect ion channel functional properties, including ion conductance, desensitization, and ligand binding (Villmann et al., 2009). Previous studies demonstrated highly reduced surface expression and complete loss of glycine-induced currents for most TM3-4 loop mutations in a homomeric receptor configuration (Chung et al., 2010; Bode et al., 2013; Schaefer et al., 2015).

In contrast, $\alpha 1^{\mathrm{P} 366 \mathrm{~L}}$ expression levels were indistinguishable from $\alpha 1^{\text {wt }}$ protein. Recombinant expression of $\alpha 1^{\mathrm{P} 366 \mathrm{~L}}$ as well as exchanges of proline to alanine, arginine, and threonine demonstrated that position 366 substantially affected glycine-gated chloride currents. These data suggest that side chain volume and polarity at residue 366 per se are not the main limiting factor affecting GlyR physiology. Moreover, the $\sim 25 \%$ reduction in maximal current responses detected in $\alpha 1^{\mathrm{P} 366 \mathrm{~L}}$ is not a result of decreased membrane incorporation or ER retention as demonstrated for other intracellular loop mutations (Villmann et al., 2009; Bode et al., 2013). Instead, global conformational changes induced by the proline-to-leucine exchange are more likely to account for reduced inward currents.

Synaptic GlyRs are expressed as heteromeric protein complexes composed of $\alpha 1$ and $\beta$ subunits representing the major adult isoform in the human spinal cord and brainstem nuclei (Patrizio et al., 2017). For mutations $\alpha 1^{\mathrm{E} 375 \mathrm{X}}, \alpha 1^{\mathrm{D} 388 \mathrm{~A}}$, and 
A
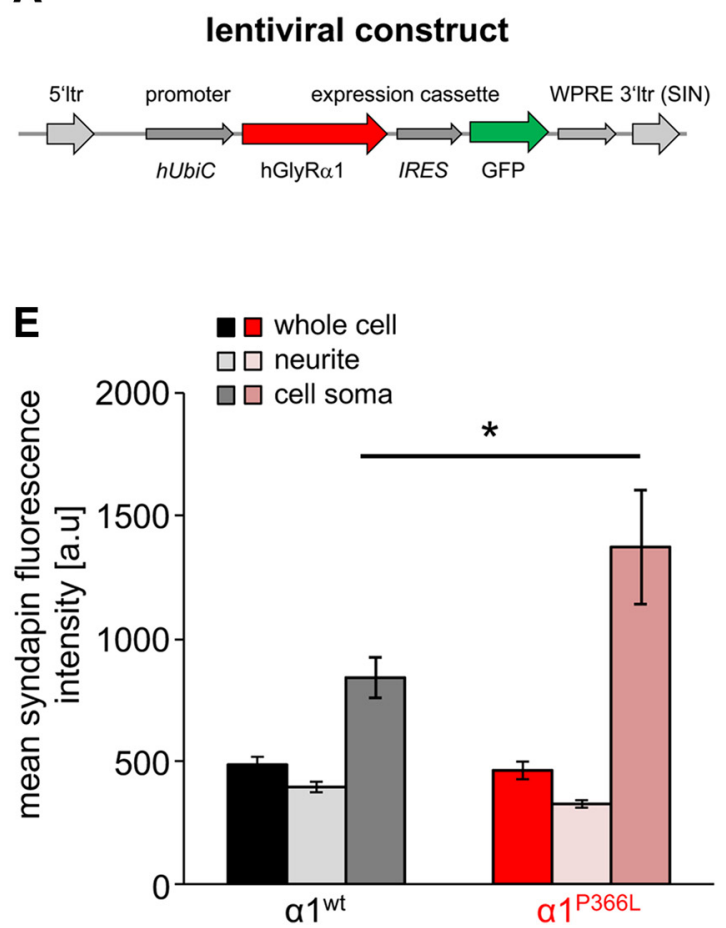

B

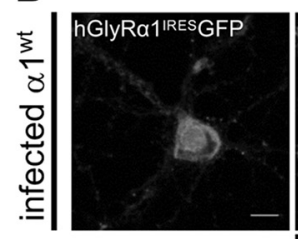

C
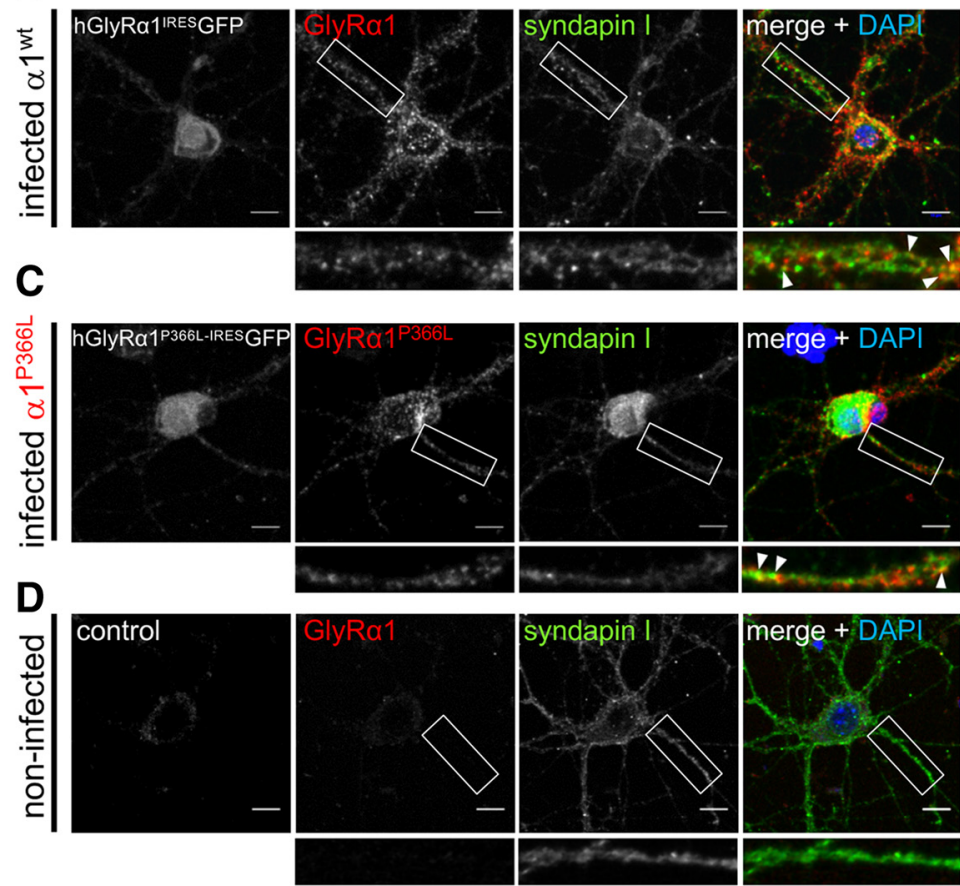

Figure 10. Expression of $\alpha 1^{\mathrm{P} 366 \mathrm{~L}}$ in infected primary hippocampal neurons changes endogenous syndapin I distribution. $\boldsymbol{A}$, Schematic overview of the lentiviral vector construct expressing GlyR $\alpha 1$ or GlyR $\alpha 1^{\text {P366L }}$. The lentiviral vector is based on the self-inactivating (SIN) vector backbone FUGW (Lois et al., 2002). The human ubiquitin C ( $h$ UbiC) promoter drives expression of human GlyR $\alpha 1$ or the mutated variant GlyR $\alpha 1^{\text {P366L }}$. An internal ribosomal entry site (IRES) is used for bicistronic expression of GFP. LTR, Long-terminal repeat; WPRE, Woodchuck Hepatitis Virus (WHP) Post-transcriptional Regulatory Element. $\boldsymbol{B}, \boldsymbol{C}$, Cell surface expressions of $\alpha 1^{\text {wt }}(\boldsymbol{B})$ and $\alpha 1^{\mathrm{P} 366 \mathrm{~L}}(\boldsymbol{C})$ were determined in live stainings with the $\alpha 1$-specific antibody mAb2b recognizing a native epitope in the far N-terminal part of GlyR $\alpha 1$ (red). After permeabilization of cells, endogenous syndapin I was visualized with the rabbit anti-syndapin I antibody (green). Note that expression of the mutant $\alpha 1^{\mathrm{P} 366 \mathrm{~L}}$ redistributed endogenous syndapin I to the cell soma. $\boldsymbol{D}$, Expression of endogenous $\alpha 1$ GlyR and syndapin I in uninfected hippocampal primary neurons.

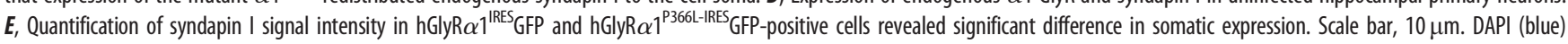
staining marks DNA (nucleus). ${ }^{*} p<0.05$.

$\alpha 1^{\mathrm{R} 392 \mathrm{H}}$, a rescue of protein function by coexpression with the GlyR $\beta$ subunit has been described (Chung et al., 2010; Bode et al., 2013). Here, the presence of GlyR $\beta$ had no supportive effect on the glycine potency when coexpressed with the $\alpha 1^{\mathrm{P} 366 \mathrm{~L}}$. Furthermore, the glycine efficacy of the mutant GlyR $\alpha 1^{\mathrm{P} 366 \mathrm{~L}}$ was unaltered in the presence and absence of the coexpressed $\beta$ subunit.

The proline 366-to-leucine mutation seems not to influence the extracellular ligand binding or associated structural transitions. Our findings from voltage-clamp fluorometry recordings support this conclusion. Labeling of extracellular residues N203 or R271 (Pless and Lynch, 2009) showed no further changes in fluorescence when $\alpha 1^{\mathrm{P} 366 \mathrm{~L}}$ was present.

Because of the location of proline 366 in a PPII helix, which may change its helical structure when proline is mutated to leucine, we speculated that $\alpha 1^{\mathrm{P} 366 \mathrm{~L}}$ alters intracellular conformational rearrangements of the GlyR that occur in the processes of channel opening, desensitizing, and closing. Several in vitro studies demonstrated that small variations of the GlyR $\alpha 1, G A B A_{A} R$, or 5- $\mathrm{HT}_{3 \mathrm{~A}} \mathrm{R}$ TM3-4 loop sequences affect desensitization kinetics (Hu et al., 2006; O’Toole and Jenkins, 2011; Langlhofer et al., 2015).

The analysis of the channel kinetics revealed that proline 366 mutations to leucine, alanine, and cysteine produced GlyRs with accelerated whole-cell desensitization. An enhanced fraction of desensitizing currents in other intracellular mutations $\alpha 1^{\mathrm{P} 250 \mathrm{~T}}$ and $\alpha 1^{\mathrm{A} 384 \mathrm{P}}$ has previously been reported to account for disturbed glycinergic neurotransmission and human startle disease (Breitinger et al., 2001; Wang et al., 2018). In the case of $\mathrm{P} 250 \mathrm{~T}$, the loss of an angular polypeptide structure was thought to destabilize the open channel conformation due to the close proximity to the pore lining TM2 (Saul et al., 1999). The pathophysiological importance of CLR desensitization is emphasized by several studies that connected changes in receptor kinetics to pathologic processes observed in different neurologic disorders (e.g., changes in $\mathrm{nAChR}$ desensitization rates associated with the development of frontal lobe epilepsy and congenital myasthenic syndrome; Sine et al., 2002). However, the observed increase in whole-cell desensitization of $\alpha 1^{\mathrm{P} 366 \mathrm{~L}}$ is small compared with the channel-destabilizing hyperekplexia mutant $\alpha 1^{\mathrm{P} 250 \mathrm{~T}}$. The so far determined minor effects of the mutant $\alpha 1^{\mathrm{P} 366 \mathrm{~L}}$ on receptor desensitization, the unchanged glycine sensitivity, and the unaltered surface expression also explain the lack of changes in the IPSCs obtained from artificial synapse recordings.

Our findings of reduced peak current in heteromeric $\alpha 1^{\mathrm{P} 366 \mathrm{~L}} \beta$ receptors in whole-cell recordings were consistent with reduced conductance at the single-channel level. A significant decrease in single-channel conductance induced by $\alpha 1^{\mathrm{P} 366 \mathrm{~L}}$ was observed similar to other mutations associated with hereditary hyperekplexia (Saul et al., 1999; Bode and Lynch, 2013). In respect of the spinal motor reflex arcs, it is accepted that reduction in glycinergic magnitudes disinhibit motoneurons and thereby enhance their excitability, leading to the increased frequency of muscle contractions. 
Furthermore, we found $\alpha 1^{\mathrm{P} 366 \mathrm{~L}} \beta$ receptors to open sporadically in the absence of extracellular glycine. The sporadic opening of $\alpha 1^{\mathrm{P} 366 \mathrm{~L}} \beta$ is not due to a reduced number of receptors in the patch as surface expression of the mutant $\alpha 1^{\mathrm{P} 366 \mathrm{~L}}$ was similar to that of $\alpha 1^{\mathrm{wt}}$ receptors. Tonic GlyR activity has also been identified in other autosomal-dominant inherited hyperekplexia mutations $\alpha 1^{\mathrm{Y} 128 \mathrm{C}}, \alpha 1^{\mathrm{Q} 226 \mathrm{E}}, \alpha 1^{\mathrm{V} 280 \mathrm{M}}$, and $\alpha 1^{\mathrm{R} 414 \mathrm{H}}$ (Chung et al., 2010; Bode and Lynch, 2013).

An increase in spontaneous activity can be easily explained by a concomitant decrease in glycine $\mathrm{EC}_{50}$, which is, however, not observed for $\alpha 1^{\mathrm{P} 366 \mathrm{~L}} \beta$. This is in line with $\alpha 1^{\mathrm{Q} 226 \mathrm{E}}$ not affecting the glycine $\mathrm{EC}_{50}$, whereas $\alpha 1^{\mathrm{V} 280 \mathrm{M}}$ significantly decreased and $\alpha 1^{\mathrm{R} 414 \mathrm{H}}$ slightly increased the $\mathrm{EC}_{50}$ for the agonist glycine (Bode et al., 2013). Studies on $\alpha 1^{\mathrm{Q} 226 \mathrm{E}}$ and $\alpha 1^{\mathrm{V} 280 \mathrm{M}}$ provided evidence using molecular modeling for channel widening at the cytoplasmic exit caused by these hyperekplexia mutations. Considering the distance of P366 from the transmembrane domain, it is more likely that $\alpha 1^{\mathrm{P} 366 \mathrm{~L}}$ causes intracellular structural changes most likely of the PPII helix that influence spontaneous channel opening. Spontaneous opening events of $\alpha 1^{\mathrm{P} 366 \mathrm{~L}} \beta$ were, however, less frequent than in $\alpha 1^{\mathrm{Q} 226 \mathrm{E}}$, suggesting that tonic activity alone might not explain the hyperekplexia phenotype observed (Scott et al., 2015). Furthermore, the $\alpha 1^{\mathrm{P} 366 \mathrm{~L}}$ mutation resulted in a net reduction of channel conductance. This was due to a smaller main conductance level in the mutant and the identification of low-conductance states that were not observed in the $\alpha 1^{\mathrm{wt}}$.

From our data, we cannot rule out that $\alpha 1^{\mathrm{P} 366 \mathrm{~L}}$ disrupts the homomeric presynaptic GlyR function that regulates inhibitory transmitter release and thereby generates imbalances of inhibition and excitation in adjacent motoneurons (Turecek and Trussell, 2001; Xiong et al., 2014). Moreover, mutant $\alpha 1^{\mathrm{P} 366 \mathrm{~L}}$ might undergo protein-protein interactions with presynaptic and extrasynaptic $\mathrm{GABA}_{\mathrm{A}}$ Rs impairing additionally GABAergic inhibition and, thus, contributing to the disease pathology of human startle disease (Zou et al., 2019).

The TM3-4 loops of both, GlyR $\alpha 1$ and $\beta$ subunits contain proline-rich subdomains that have previously been demonstrated to create consensus sequences for the binding of $\mathrm{SH} 3$ domains (Cascio et al., 2001; Breitinger et al., 2004), and other PPII helix-binding partners. Recently, it has been pointed out that the dominant mode of ligand recognition of the SH3 domains involves interactions between poly-prolines and the PXXP-binding site, but noncanonical or multiple specificities are also common (Teyra et al., 2017). We found that syndapin I was bound to the GlyR $\alpha 1$ peptide ${ }^{362}$ TTNPPPAPSKSPC ${ }^{374}$, including the P366 locus as well as to the GlyR $\beta$ peptide ${ }^{433} \mathrm{NK}$ $\mathrm{KPPPAKPVIPC}^{445}$. Our analysis clearly demonstrated the accumulation of syndapin I and endophilin in probes containing one of those peptides. These results are consistent with a study showing that syndapin I and endophilin I bind to overlapping proline-rich regions of dynamin I (Anggono and Robinson, 2007). The interaction between GlyR $\alpha 1$ and syndapin I was significantly diminished by the mutation of proline 366 to alanine or leucine at least in the peptide array approach. Similarly, the interaction of TRPV4 channels and syndapin three mediated by a proline-rich region with consecutive "PPP" residues was significantly weakened by an amino acid substitution of the second proline to either an leucine or an alanine (Goretzki et al., 2018).

The C-terminal SH3 domain of syndapin I is crucial for endocytosis, cytoskeletal remodeling, and postsynapse formation (Qualmann and Kelly, 2000; Dharmalingam et al., 2009;
Schneider et al., 2014; Luo et al., 2016). Syndapin I is present at excitatory and inhibitory synapses. Syndapin I has been demonstrated to regulate AMPA receptor trafficking, internalization, degradation, and recycling processes, thus regulating synaptic strength of excitatory synapses (Quan and Robinson, 2013; Widagdo et al., 2016). Interestingly, syndapin I knock-out mice display generalized seizures, defects in excitatory and inhibitory synaptic transmission, impairments in vesicle formation and impairment of dynamin recruitment (Koch et al., 2011). Binding of syndapin I to the $\operatorname{GlyR} \beta$ subunit has been shown with decreased GlyR cluster sizes and densities on syndapin I knockout (Del Pino et al., 2014). We observed a strong increase in syndapin I signal intensity in the soma of cells and a slight decrease in the neurites expressing the mutant $\alpha 1^{\mathrm{P} 366 \mathrm{~L}}$ compared with $\alpha 1^{\mathrm{wt}}$. Our results suggest that the interaction between the mutated poly-proline subdomain in $\alpha 1^{\mathrm{P} 366 \mathrm{~L}}$ and the $\mathrm{SH} 3$ domain of syndapin I changes the protein distribution in hippocampal neurons. Therefore, syndapin I might potentially act as a regulator for GlyR trafficking to neurite membranes. However, a distinct role of syndapin I in GlyR dynamics needs further investigation in an appropriate in vivo model. Together, we identified the GlyR $\alpha 1$ subunit contributing to interactions with intracellular binding partners important for receptor trafficking, a function thus far only ascribed to the GlyR $\beta$ subunit.

We demonstrate that the patient GlyR mutation $\alpha 1^{\mathrm{P} 366 \mathrm{~L}}$ exhibits multiple functional deficits of the inhibitory GlyRs, including decreased single-channel conductance, accelerated receptor desensitization kinetics, spontaneous channel opening, and reduced interaction with F-BAR protein syndapin I, hence providing experimental evidence explaining the neuromotor phenotype of the startle disease patient.

\section{References}

Anggono V, Robinson PJ (2007) Syndapin I and endophilin I bind overlapping proline-rich regions of dynamin I: role in synaptic vesicle endocytosis. J Neurochem 102:931-943.

Atak S, Langlhofer G, Schaefer N, Kessler D, Meiselbach H, Delto C, Schindelin H, Villmann C (2015) Disturbances of ligand potency and enhanced degradation of the human glycine receptor at affected positions G160 and T162 originally identified in patients suffering from hyperekplexia. Front Mol Neurosci 8:79.

Bakker MJ, van Dijk JG, van den Maagdenberg AM, Tijssen MA (2006) Startle syndromes. Lancet Neurol 5:513-524.

Bocquet N, Nury H, Baaden M, Le Poupon C, Changeux JP, Delarue M, Corringer PJ (2009) X-ray structure of a pentameric ligand-gated ion channel in an apparently open conformation. Nature 457:111-114.

Bode A, Lynch JW (2013) Analysis of hyperekplexia mutations identifies transmembrane domain rearrangements that mediate glycine receptor activation. J Biol Chem 288:33760-33771.

Bode A, Lynch JW (2014) The impact of human hyperekplexia mutations on glycine receptor structure and function. Mol Brain 7:2.

Bode A, Wood S-E, Mullins JGL, Keramidas A, Cushion TD, Thomas RH, Pickrell WO, Drew CJG, Masri A, Jones EA, Vassallo G, Born AP, Alehan F, Aharoni S, Bannasch G, Bartsch M, Kara B, Krause A, Karam EG, Matta S, et al. (2013) New hyperekplexia mutations provide insight into glycine receptor assembly, trafficking, and activation mechanisms. J Biol Chem 288:33745-33759.

Breitinger HG, Villmann C, Becker K, Becker CM (2001) Opposing effects of molecular volume and charge at the hyperekplexia site alpha 1(P250) govern glycine receptor activation and desensitization. J Biol Chem 276:29657-29663.

Breitinger HG, Villmann C, Rennert J, Ballhausen D, Becker CM (2002) Hydroxylated residues influence desensitization behaviour of recombinant alpha3 glycine receptor channels. J Neurochem 83:30-36.

Breitinger U, Breitinger HG, Bauer F, Fahmy K, Glockenhammer D, Becker CM (2004) Conserved high affinity ligand binding and membrane 
association in the native and refolded extracellular domain of the human glycine receptor alpha1-subunit. J Biol Chem 279:1627-1636.

Burgos CF, Castro PA, Mariqueo T, Bunster M, Guzman L, Aguayo LG (2015) Evidence for $\alpha$-helices in the large intracellular domain mediating modulation of the $\alpha 1$-glycine receptor by ethanol and G $\beta \gamma$. J Pharmacol Exp Ther 352:148-155.

Carta E, Chung S-K, James VM, Robinson A, Gill JL, Remy N, Vanbellinghen J-F, Drew CJG, Cagdas S, Cameron D, Cowan FM, Del Toro M, Graham GE, Manzur AY, Masri A, Rivera S, Scalais E, Shiang R, Sinclair K, Stuart CA, et al. (2012) Mutations in the GlyT2 gene (SLC6A5) are a second major cause of startle disease. J Biol Chem 287:28975-28985.

Cascio M, Shenkel S, Grodzicki RL, Sigworth FJ, Fox RO (2001) Functional reconstitution and characterization of recombinant human alpha 1-glycine receptors. J Biol Chem 276:20981-20988.

Chung S-K, Vanbellinghen J-F, Mullins JGL, Robinson A, Hantke J, Hammond CL, Gilbert DF, Freilinger M, Ryan M, Kruer MC, Masri A, Gurses C, Ferrie C, Harvey K, Shiang R, Christodoulou J, Andermann F, Andermann E, Thomas RH, Harvey RJ, et al. (2010) Pathophysiological mechanisms of dominant and recessive GLRA1 mutations in hyperekplexia. J Neurosci 30:9612-9620.

Cox J, Mann M (2008) MaxQuant enables high peptide identification rates, individualized p.p.b.-range mass accuracies and proteome-wide protein quantification. Nat Biotechnol 26:1367-1372.

Del Pino I, Koch D, Schemm R, Qualmann B, Betz H, Paarmann I (2014) Proteomic analysis of glycine receptor $\beta$ subunit $(\mathrm{GlyR} \beta)$-interacting proteins: evidence for syndapin I regulating synaptic glycine receptors. J Biol Chem 289:11396-11409.

Dharmalingam E, Haeckel A, Pinyol R, Schwintzer L, Koch D, Kessels MM, Qualmann B (2009) F-BAR proteins of the syndapin family shape the plasma membrane and are crucial for neuromorphogenesis. J Neurosci 29:13315-13327.

Du J, Lü W, Wu S, Cheng Y, Gouaux E (2015) Glycine receptor mechanism elucidated by electron cryo-microscopy. Nature 526:224-229.

Goretzki B, Glogowski NA, Diehl E, Duchardt-Ferner E, Hacker C, Gaudet R, Hellmich UA (2018) Structural basis of TRPV4 N terminus interaction with syndapin/PACSIN1-3 and PIP2. Structure 26:1583-1593.e5.

Goyal R, Salahudeen AA, Jansen M (2011) Engineering a prokaryotic Cysloop receptor with a third functional domain. J Biol Chem 286:3463534642.

Harvey K, Duguid IC, Alldred MJ, Beatty SE, Ward H, Keep NH, Lingenfelter SE, Pearce BR, Lundgren J, Owen MJ, Smart TG, Lüscher B, Rees MI, Harvey RJ (2004) The GDP-GTP exchange factor collybistin: an essential determinant of neuronal gephyrin clustering. J Neurosci 24: 5816-5826.

Hilf RJ, Dutzler R (2009) Structure of a potentially open state of a protonactivated pentameric ligand-gated ion channel. Nature 457:115-118.

Hu XQ, Sun H, Peoples RW, Hong R, Zhang L (2006) An interaction involving an arginine residue in the cytoplasmic domain of the 5-HT3A receptor contributes to receptor desensitization mechanism. J Biol Chem 281:21781-21788.

Kessels MM, Qualmann B (2004) The syndapin protein family: linking membrane trafficking with the cytoskeleton. J Cell Sci 117:3077-3086.

Koch D, Spiwoks-Becker I, Sabanov V, Sinning A, Dugladze T, Stellmacher A, Ahuja R, Grimm J, Schüler S, Müller A, Angenstein F, Ahmed T, Diesler A, Moser M, Tom Dieck S, Spessert R, Boeckers TM, Fässler R, Hübner CA, Balschun D, et al. (2011) Proper synaptic vesicle formation and neuronal network activity critically rely on syndapin I. EMBO J 30:4955-4969.

Langlhofer G, Villmann C (2016) The intracellular loop of the glycine receptor: it's not all about the size. Front Mol Neurosci 9:41.

Langlhofer G, Janzen D, Meiselbach H, Villmann C (2015) Length of the TM3-4 loop of the glycine receptor modulates receptor desensitization. Neurosci Lett 600:176-181.

Lois C, Hong EJ, Pease S, Brown EJ, Baltimore D (2002) Germline transmission and tissue-specific expression of transgenes delivered by lentiviral vectors. Science 295:868-872.

Luo L, Xue J, Kwan A, Gamsjaeger R, Wielens J, von Kleist L, Cubeddu L, Guo Z, Stow JL, Parker MW, Mackay JP, Robinson PJ (2016) The binding of syndapin SH3 domain to dynamin proline-rich domain involves short and long distance elements. J Biol Chem 291:9411-9424.
Lynch JW (2004) Molecular structure and function of the glycine receptor chloride channel. Physiol Rev 84:1051-1095.

Maric HM, Kasaragod VB, Hausrat TJ, Kneussel M, Tretter V, Stromgaard $\mathrm{K}$, Schindelin H (2014) Molecular basis of the alternative recruitment of $\mathrm{GABA}(\mathrm{A})$ versus glycine receptors through gephyrin. Nat Comm 5:5767.

Maric HM, Hausrat TJ, Neubert F, Dalby NO, Doose S, Sauer M, Kneussel M, Strømgaard K (2017) Gephyrin-binding peptides visualize postsynaptic sites and modulate neurotransmission. Nat Chem Biol 13:153-160.

Masuda T, Tomita M, Ishihama Y (2008) Phase transfer surfactant-aided trypsin digestion for membrane proteome analysis. J Proteome Res 7:731-740.

O’Toole KK, Jenkins A (2011) Discrete M3-M4 intracellular loop subdomains control specific aspects of $\gamma$-aminobutyric acid type A receptor function. J Biol Chem 286:37990-37999.

Papke D, Grosman C (2014) The role of intracellular linkers in gating and desensitization of human pentameric ligand-gated ion channels. J Neurosci 34:7238-7252

Patrizio A, Renner M, Pizzarelli R, Triller A, Specht CG (2017) Alpha subunit-dependent glycine receptor clustering and regulation of synaptic receptor numbers. Sci Rep 7:10899.

Pless SA, Lynch JW (2009) Ligand-specific conformational changes in the alpha1 glycine receptor ligand-binding domain. J Biol Chem 284:1584715856

Pless SA, Dibas MI, Lester HA, Lynch JW (2007) Conformational variability of the glycine receptor M2 domain in response to activation by different agonists. J Biol Chem 282:36057-36067.

Qualmann B, Kelly RB (2000) Syndapin isoforms participate in receptormediated endocytosis and actin organization. J Cell Biol 148:10471062.

Qualmann B, Roos J, DiGregorio PJ, Kelly RB (1999) Syndapin I, a synaptic dynamin-binding protein that associates with the neural Wiskott-Aldrich syndrome protein. Mol Biol Cell 10:501-513.

Quan A, Robinson PJ (2013) Syndapin -a membrane remodelling and endocytic F-BAR protein. FEBS J 280:5198-5212.

Rappsilber J, Ishihama Y, Mann M (2003) Stop and go extraction tips for matrix-assisted laser desorption/ionization, nanoelectrospray, and LC/MS sample pretreatment in proteomics. Anal Chem 75:663-670.

Saul B, Kuner T, Sobetzko D, Brune W, Hanefeld F, Meinck HM, Becker CM (1999) Novel GLRA1 missense mutation (P250T) in dominant hyperekplexia defines an intracellular determinant of glycine receptor channel gating. J Neurosci 19:869-877.

Schaefer N, Kluck CJ, Price KL, Meiselbach H, Vornberger N, Schwarzinger S, Hartmann S, Langlhofer G, Schulz S, Schlegel N, Brockmann K, Lynch B, Becker CM, Lummis SC, Villmann C (2015) Disturbed neuronal ERGolgi sorting of unassembled glycine receptors suggests altered subcellular processing is a cause of human hyperekplexia. J Neurosci 35: 422-437.

Schneider K, Seemann E, Liebmann L, Ahuja R, Koch D, Westermann M, Hübner CA, Kessels MM, Qualmann B (2014) ProSAP1 and membrane nanodomain-associated syndapin I promote postsynapse formation and function. J Cell Biol 205:197-215.

Schwintzer L, Koch N, Ahuja R, Grimm J, Kessels MM, Qualmann B (2011) The functions of the actin nucleator Cobl in cellular morphogenesis critically depend on syndapin I. EMBO J 30:3147-3159.

Scott S, Lynch JW, Keramidas A (2015) Correlating structural and energetic changes in glycine receptor activation. J Biol Chem 290:5621-5634.

Sine SM, Shen XM, Wang HL, Ohno K, Lee WY, Tsujino A, Brengmann J, Bren N, Vajsar J, Engel AG (2002) Naturally occurring mutations at the acetylcholine receptor binding site independently alter ACh binding and channel gating. J Gen Physiol 120:483-496.

Teyra J, Huang H, Jain S, Guan X, Dong A, Liu Y, Tempel W, Min J, Tong Y, Kim PM, Bader GD, Sidhu SS (2017) Comprehensive analysis of the human SH3 domain family reveals a wide variety of non-canonical specificities. Structure 25:1598-1610.e3.

Tsuriel S, Geva R, Zamorano P, Dresbach T, Boeckers T, Gundelfinger ED, Garner CC, Ziv NE (2006) Local sharing as a predominant determinant of synaptic matrix molecular dynamics. PLoS Biol 4:e271.

Turecek R, Trussell LO (2001) Presynaptic glycine receptors enhance transmitter release at a mammalian central synapse. Nature 411:587590 . 
Villmann C, Oertel J, Melzer N, Becker CM (2009) Recessive hyperekplexia mutations of the glycine receptor alphal subunit affect cell surface integration and stability. J Neurochem 111:837-847.

Wang $\mathrm{CH}$, Hernandez CC, Wu J, Zhou N, Hsu HY, Shen ML, Wang YC, Macdonald RL, Wu DC (2018) A missense mutation A384P associated with human hyperekplexia reveals a desensitization site of glycine receptors. J Neurosci 38:2818-2831.

Wessel D, Flügge UI (1984) A method for the quantitative recovery of protein in dilute solution in the presence of detergents and lipids. Anal Biochem 138:141-143.

Widagdo J, Fang H, Jang SE, Anggono V (2016) PACSIN1 regulates the dynamics of AMPA receptor trafficking. Sci Rep 6:31070.

Xiong W, Chen SR, He L, Cheng K, Zhao YL, Chen H, Li DP, Homanics GE, Peever J, Rice KC, Wu LG, Pan HL, Zhang L (2014) Presynaptic glycine receptors as a potential therapeutic target for hyperekplexia disease. Nat Neurosci 17:232-239.

Yang Z, Taran E, Webb TI, Lynch JW (2012) Stoichiometry and subunit arrangement of $\alpha 1 \beta$ glycine receptors as determined by atomic force microscopy. Biochemistry 51:5229-5231.

Zhang Y, Dixon CL, Keramidas A, Lynch JW (2015) Functional reconstitution of glycinergic synapses incorporating defined glycine receptor subunit combinations. Neuropharmacology 89:391-397.

Zou G, Chen Q, Chen K, Zuo X, Ge Y, Hou Y, Pan T, Pan H, Liu D, Zhang L, Xiong W (2019) Human hyperekplexic mutations in glycine receptors disinhibit the brainstem by hijacking $\mathrm{GABA}_{\mathrm{A}}$ receptors. iScience 19:634-646.

Zufferey R, Dull T, Mandel RJ, Bukovsky A, Quiroz D, Naldini L, Trono D (1998) Self-inactivating lentivirus vector for safe and efficient in vivo gene delivery. J Virol 72:9873-9880. 